\title{
A zonally-oriented teleconnection pattern induced by heating of the western Tibetan Plateau in boreal summer
}

\author{
Qingquan $\mathrm{Li}^{1,2} \cdot$ Mengchu Zhao ${ }^{1,2} \cdot$ Song Yang ${ }^{3,4} \cdot$ Xinyong Shen ${ }^{2,4} \cdot$ Lili Dong $^{1} \cdot$ Zhaodong Liu $^{2,5}$
}

Received: 10 January 2021 / Accepted: 8 June 2021 / Published online: 28 June 2021

(c) The Author(s) 2021

\begin{abstract}
The thermal effect of the Tibetan Plateau (TP) on the northern hemisphere climate has long been a hot topic of scientific research. However, the global effects of the TP heat source are still unclear. We investigate the teleconnection patterns coincident with the TP heat source in boreal summer using both observational data and numerical models including a linearized baroclinic model and an atmospheric general circulation model. The western TP shows the most intense variability in atmospheric heating and the most active connection to atmospheric circulations. The surface sensible heating component of the western TP heat source is associated with a high-latitude wave train propagating from North Japan to central North America through the Bering Sea and Canada. The radiative heating component is accompanied by a wavenumber- 4 wave train over Eurasia. We focus on the global zonally-oriented pattern that is connected with the latent heat release from the western $\mathrm{TP}$, referred to here as the TP-circumglobal teleconnection (TP-CGT). The TP-CGT pattern is triggered by the western TP latent heating in two parts starting from the TP: an eastward-propagating wave train trapped in the westerly jet stream and a westward Rossby wave response. The TP-CGT accounts for above $18 \%$ of the total variance of the circumglobal teleconnection pattern and modulates mid-latitude precipitation by superimposition. The western TP is the key region in which diabatic heating can initiate the two atmospheric responses concurrently, and the heating over northeastern Asia or the Indian Peninsula is unable to induce the circumglobal pattern directly. The unique geographical location and strong tropospheric heating also make the western TP as a "transit area" of transferring the indirect impact of the Indian summer monsoon (ISM) to the TP-CGT. These results enhance our understanding of the relationship between the circumglobal teleconnection and the ISM and is helpful for improving the prediction of the circumglobal teleconnection variability.
\end{abstract}

Keywords Tibetan Plateau · Atmospheric heat source · Circumglobal teleconnection · Precipitation · Interannual variation

\section{Introduction}

The circumglobal teleconnection (CGT) is a major teleconnection pattern in the northern hemisphere in boreal summer and is characterized by several geographically-anchored

Qingquan Li

liqq@cma.gov.cn

$\triangle$ Mengchu Zhao

zmc736890225@163.com

1 Laboratory for Climate Studies, National Climate Center, China Meteorological Administration, Beijing 100081, China

2 Key Laboratory of Meteorological Disaster, Ministry of Education/Joint International Research Laboratory of Climate and Environment Change/Collaborative Innovation Center On Forecast and Evaluation action centers along the upper-tropospheric westerly jet stream (Ding and Wang 2005; Enomoto et al. 2003; Kosaka et al. 2009; Krishnan and Sugi 2001; Lu et al. 2002). The CGT exhibits a stationary Rossby wave trapped in the basic flow, which has been confirmed by the analysis of Rossby

of Meteorological Disasters, Nanjing University of Information Science and Technology, Nanjing 210044, China

3 School of Atmospheric Sciences and Guangdong Province Key Laboratory for Climate Change and Natural Disaster Studies, Sun Yat-Sen University, Zhuhai, China

4 Southern Marine Science and Engineering Guangdong Laboratory (Zhuhai), Zhuhai, China

5 State Key Laboratory of Severe Weather (LASW), Chinese Academy of Meteorological Sciences (CAMS), CMA, Beijing, China 
wavenumbers. The scale of the westerly jet stream allows the propagation of the CGT throughout the entire northern hemisphere (Ambrizzi et al. 1995; Hoskins and Ambrizzi 1993; Kosaka et al. 2009). The CGT therefore exerts more important impacts on the mid-latitude temperature, precipitation and extreme weather than the meridional teleconnections such as the Pacific-Japan pattern (Ding and Wang 2005; Hu and Nitta 1997; Hu et al.2005; Huang et al. 2011; Li et al. 2005; Nitta 1987; Sun and Wang 2012; Wang et al. 2017; Wu et al. 2016b; Yuan et al. 2015).

The CGT is a dynamic mode that can self-maintain efficiently by extracting available potential energy from the westerly jet stream (Chen et al. 2013; Kosaka et al. 2009; Sato and Takahashi 2006). The zonal asymmetries of the westerly jet stream account for the longitudinal phase-locked teleconnection centers (Kosaka et al. 2009). Previous studies have investigated the role of external forcing in the CGT and shown that the diabatic heating or cooling over the Mediterranean Sea is responsible for the CGT-like pattern and several remote areas such as North America and tropical Africa can also trigger a mid-latitude stationary Rossby wave response (Lin et al. 2017a, b; Lin and Lu 2016; Yasui and Watanabe 2010).

The effect of the Indian summer monsoon (ISM) on the CGT has been much debated, and it has been hypothesized that the ISM heat source may contribute to the maintenance of the CGT (Ding and Wang 2005, 2007). Previous studies have also highlighted the role of ISM heating in exciting the CGT pattern, especially the main centers of the CGT over the Asian sector (Krishnan and Sugi 2001; Wu 2002; $\mathrm{Wu}$ et al. 2003). The interdecadal change in the impact of diabatic heating has shown that the CGT was dominated by ISM rainfall before the 1970s and affected by both the ISM and southern European regions after the 1970s (Ding and Wang 2007; Ding et al. 2011; Lin et al. 2017a; Wu and Wang 2002). By contrast, Yasui and Watanabe (2010) showed that ISM monsoon heating contributed only a small part to the CGT variability. Such debates also surround the effects of forcing by sea surface temperature anomalies (SSTAs). A CGT-like response can be excited by a strong tropical SSTA during the summer preceding the peak phases of the El Niño Southern Oscillation, and rainfall in the ISM region can be modulated by the El Niño Southern Oscillation to enhance the CGT pattern (Ding et al. 2011). The interdecadal CGT pattern shows no significant relationship with the Atlantic multidecadal oscillation, although the CGT prefers the same phases as this oscillation (Wang et al. 2017; Wu et al. 2016a, 2018). These characteristics of the CGT not only feature a dynamic mode trapped in the jet stream, but also are sensitive to external forcing, which results in the low prediction skills of the CGT variability.

The Tibetan Plateau (TP) covers an area of 2.9 million $\mathrm{km}^{2}$ and is the highest plateau in the world with an average elevation > $4000 \mathrm{~m}$ (Qiu 2008; Yao, 2017). The high elevation and complex terrain make the plateau an area with extremely high levels of incoming shortwave radiation (Zhao and Chen 2000). Previous studies have highlighted the thermal effect of turbulent heat processes and surface radiation. The change in the surface turbulent heat flux over the southeastern TP exerts an important role in regulating Meiyu rainfall and torrential rainstorms in the Yangtze River valleys (Dong et al. 2019; Duan et al. 2013; Duan and Wu 2005; Liu et al. 2020b). Precipitation in northeastern India and the Bay of Bengal can also be forced by the air pump effect driven by the surface sensible heat flux (SSHF) of the TP (Wu and Zhang 1998). Robust connections have been found between the atmospheric circulation and the variability in snow cover on the TP (Song et al 2019; Zhao et al. 2007; Wu et al. 2014a, b). Autumn-spring snow cover over the eastern TP can affect North American temperature by largescale atmospheric wave pattern, a Pacific-North America (PNA)-like downstream atmospheric response, and a western Pacific-like teleconnection pattern is excited by anomalies in the autumn snow cover (Lin and Wu 2011; Liu et al. 2017, 2020a; Mote and Kutney 2012; Qian et al. 2019; Wang et al. 2020; $\mathrm{Wu}$ et al. 2011). The decrease in summertime snow cover can trigger a zonal wave train over Eurasia and influence $30 \%$ of the total variance in summer heat waves in southern Europe (Wu et al. 2016c).

The atmospheric heat source over the TP is formed by the SSHF, latent heat release (LH), and radiative convergence during summer (Yanai et al. 1973; Jiang et al. 2016; Jiang and Ting 2017, 2019). The impacts of the SSHF on the Earth's climate have been widely discussed (Duan et al. 2011; Liu et al. 2020b; Li et al. 2020b, 2021), although the other components of the TP heat source have received less attention. The TP presents a self-exciting feedback mechanism similar to the mechanism for tropical cyclones and efficiently extracts moisture from the low latitudes in cooperation with the summer monsoon. The latent heating release contributes $>60 \%$ of the TP HS in summer (Xu et al. 2008; Xu 2014).

The latent heat release from the tropics plays an important role in modulating the atmospheric circulation and exciting teleconnection patterns. For example, the latent heat released by the convective activity near the Philippines can propagate into the mid-latitudes as Rossby waves along the southwesterly winds in the lower troposphere (Kosaka and Nakamura 2006). We investigate whether the strong LH over the TP can cause a similar Rossby wave response along the zonallyvarying mean flow. Previous studies have shown that snow cover and the changes in the surface characteristics can force a Rossby wave response similar to specific segments of the CGT, but the impact of the western-TP (WTP) heating on the entire CGT wave train is still unclear. 
The heat source in the sub-regions of the TP, which affects the Asian monsoon and its various components differently (Lu et al. 2021), shows a nonuniform variability, especially between the WTP and the central-eastern TP. The weakening in sensible heat is more evident over the central-eastern TP (Duan and Wu 2008), but the interannual variability in the total heat source of the WTP is the opposite to that of the eastern TP (Yang et al. 2011). Previous studies based on station observations have been mainly focused on the thermal effects of the central-eastern TP and the role of WTP heating remains poorly understood (Duan et al. 2011, 2013; Wang et al. 2012; Wu et al. 2016c) as a result of sparse ground measurements. Studies using reanalysis datasets have usually concentrated on the entire TP $>3000 \mathrm{~m}$ and ignored the effect of the WTP (An et al. 2017). Focus has been on the downstream circulation anomalies related to TP heating and the effect of the TP on its upstream regions still needs to be better understood (Lu et al. 2018; Wang et al. 2019).

A singular value decomposition (SVD) analysis of the heat source over the TP and the 200-hPa geopotential height (H200) over the northern hemisphere shows that the WTP exhibits a clear teleconnection with the upper-tropospheric circulation. We investigate the effects of various components and different elevation of WTP heating and discuss the zonally-oriented circumglobal teleconnection pattern induced by the latent heat release from the WTP. The role of WTP heating in forming the CGT-like pattern is shown by welldesigned numerical experiments with hierarchical models ranging from the linearized barotropic model (LBM) to an atmospheric general circulation model (AGCM).

The remainder of this paper is organized as follows. Section 2 describes the data, methods, and numerical models used in this study. Section 3 discusses the relationship between the heating of the TP area and the northern hemisphere atmospheric circulation. Section 4 investigates the teleconnection patterns related to the WTP heat source anomalies, including the TP-CGT. Section 5 presents the mechanism for the TP-CGT by statistical analysis and model simulations. Our discussion and conclusions are presented in Sect. 6.

\section{Data, methods and numerical experiments}

\subsection{Data}

We use daily atmospheric data from the US National Center for Environmental Prediction/Department of Energy (NCEP/ DOE) reanalysis dataset version 2 (NCEP-2) (Kanamitsu et al. 2002) from 1980 to 2018 with a horizontal resolution of $2.5^{\circ} \times 2.5^{\circ}$ and 17 standard pressure levels. The accuracy of the heat source is highly dependent on the quality of the reanalysis products over the TP and therefore other two state-of-the-art reanalysis datasets are selected to corroborate our results: the National Aeronautics and Space Administration (NASA) Modern-Era Retrospective Analysis for Research and Applications version 2 (MERRA-2) (Gelaro 2017) and the European Centre for Medium-Range Weather Forecasts (ECMWF) Reanalysis 5 (ERA5) datasets (Hersbach 2020). Our results show the same robust relationship between the TP heating and atmospheric circulation as the NCEP-2 product (figures not shown) and therefore only the results from the NCEP-2 dataset are shown.

The monthly mean variables of the NCEP-2 dataset include the SSHF and the precipitation rate. The radiation fluxes at the top of the atmosphere and at the surface are used to detect the different effects of the three components of the WTP heat source. We also use monthly land precipitation data from the Climatic Research Unit (CRU) TimeSeries version 4.03 (Harris et al. 2020) to investigate the rainfall anomalies affected by the variability of WTP heating through the TP-CGT. The horizontal resolution of the CRU data is $0.5^{\circ} \times 0.5^{\circ}$.

\subsection{Methods}

The atmospheric heat rate at standard pressure levels is calculated following the method of Yanai et al. (1973). The equation can be written as:

$Q_{L}=C_{P}\left[\frac{\partial T}{\partial t}+\vec{V} \cdot \nabla T+\left(\frac{p}{p_{0}}\right)^{R / C_{P}} \omega \frac{\partial \theta}{\partial p}\right]$

where $Q_{L}$ is the atmospheric heat rate, $C_{P}=1005 \mathrm{~J} \bullet \mathrm{kg}^{-1} \mathrm{~K}^{-1}$ is the specific heat of dry air, and $\overrightarrow{\boldsymbol{V}}, T$ and $p$ are the horizontal wind, temperature and pressure, respectively. $p_{0}$ $=1000 \mathrm{hPa}$. $R, \omega$ and $\theta$ are the gas constant, vertical velocity and potential temperature, respectively.

The vertically integrated tropospheric heat source (HS) is calculated from the equation:

$\mathrm{HS}=\frac{1}{g} \int_{100}^{p_{0}} Q_{L} d p \approx \mathrm{Q}_{\mathrm{R}}+\mathrm{LH}+\mathrm{SH}$

where $g$ means the gravity. The $H S$ is composed of the radiative convergence of the air column $\left(Q_{\mathrm{R}}\right)$, the latent heat release (LH) and the SSHF (SH) (Yanai 1961), the first two components are calculated as follows:

$Q_{\mathrm{R}}=S_{\infty}^{\downarrow}-S_{\infty}^{\uparrow}-L_{\infty}^{\uparrow}+S_{0}^{\uparrow}+L_{0}^{\uparrow}-S_{0}^{\downarrow}-L_{0}^{\downarrow}$

$\mathrm{LH}=\mathrm{Lw} \bullet P$

where $S, L$ and $P$ are the shortwave, longwave radiation fluxes and precipitation, respectively. The $\mathrm{Lw}=2,500,632$ 
$\mathrm{Jkg}^{-1}$. The subscripts $\infty$ and 0 denotes the top of the atmosphere and the surface, the symbol $\uparrow$ and $\downarrow$ denote the upward and downward radiation fluxes, respectively.

The local barotropic energy conversions (denoted as CK) (Hoskins and Ambrizzi 1993; Kosaka and Nakamura 2006; Kosaka et al. 2009) associated with the TP-CGT pattern are also calculated:

$\mathrm{CK}=\frac{v^{\prime^{2}}-u^{\prime^{2}}}{2}\left(\frac{\partial \bar{u}}{\partial x}-\frac{\partial \bar{v}}{\partial y}\right)-u^{\prime} v^{\prime}\left(\frac{\partial \bar{u}}{\partial y}+\frac{\partial \bar{v}}{\partial x}\right)$

where $u$ and $v$ denote the zonal and meridional wind velocity, respectively. The overbars and primes represent the climatological mean fields and anomalies, respectively. The first and second terms on the right-hand side of Eq. (5) represent the barotropic energy conversions associated with zonal variations $\left(\mathrm{CK}_{\mathrm{x}}\right)$ and the meridional shear $\left(\mathrm{CK}_{\mathrm{y}}\right)$ of the climatological mean field, respectively. A positive value of CK means that the circulation anomaly extracts kinetic energy from the summer basic flow, and vice versa. The extended Eliassen-Palm (EP) flux $E=\left(v^{\prime 2}-u^{\prime 2},-u^{\prime} v^{\prime}\right)$ of Hoskins and Ambrizzi (1993) is used to represented the propagation of CK.

Wave activity flux (WAF) is used to diagnose the energy propagation of stationary Rossby waves. The zonal and meridional components of the WAF are calculated following Takaya and Nakamura (2001):

$\mathrm{W}=\frac{1}{2|\bar{U}|}\left\{\begin{array}{l}\bar{u}\left(\psi_{x}^{\prime 2}-\psi^{\prime} \psi_{x x}^{\prime}\right)+\bar{v}\left(\psi_{x}^{\prime} \psi_{y}^{\prime}-\psi^{\prime} \psi_{x y}^{\prime}\right) \\ \bar{u}\left(\psi_{x}^{\prime} \psi_{y}^{\prime}-\psi^{\prime} \psi_{x y}^{\prime}\right)+\bar{v}\left(\psi_{y}^{\prime 2}-\psi^{\prime} \psi_{y y}^{\prime}\right)\end{array}\right.$

where $|U|$ denotes the magnitude of the horizonal wind speed and $\psi$ is the stream function. The overbar represents the climatological mean. The subscript and prime notations denote the partial derivatives and anomalies, respectively.

To eliminate the climate warming effect, the long-term trends during the time period 1980-2018 are removed after calculating the summer mean (June-September, JJAS) variables. Empirical orthogonal function (EOF) analysis is used to capture the spatiotemporal variations of the CGT instead of the one-point correlation. The first two dominant related modes between diabatic heating over the TP and the surrounding area and $\mathrm{H} 200$ are detected by the SVD method (Bretherton et al. 1992; Liu et al. 2020a; Wallace et al. 1992). Linear regression and composite analysis are conducted to obtain the circulation patterns related to the diabatic heating over the TP, respectively. Student's $t$-test is used to calculate the confidence level of the regression and composite analyses.

\subsection{Numerical models and experiment designs}

The LBM with a horizontal resolution of T42 and 20 sigma vertical levels developed by Watanabe and Kimoto (2000) is used to explore the ideal atmospheric steady response to the diabatic heating anomaly. The basic state of the LBM is taken from the summer mean (JJAS) of the NCEP-2 data climatology for the time period 1980-2018, which is consistent during the period of our study. Integration of the model is continued to 30 days after given the diabatic heating anomaly and the results averaged for days $26-30$ are shown as the steady response of the atmospheric to a prescribed diabatic heating anomaly.

The diabatic heating anomaly given to the LBM is calculated from the 3D composite difference field between strong positive and negative heating years in specific areas (see Fig. 9a). The strong positive and negative years are defined as years in which the regional mean HS exceeds one standard deviation.

The AGCM module (Community Atmospheric Model version 5.1; CAM5.1) of the Community Earth System Model developed at the National Center for Atmospheric Research (Neale et al. 2010) is used to investigate the TPCGT pattern induced by the WTP HS and to compare the results with observational analyses. The F_1850_CAM5 component set of this AGCM was used with a horizontal resolution of $1.9^{\circ} \times 2.5^{\circ}$ and 30 vertical levels. Two experiments are designed with CAM5.1, including a 40-year control run and a 40-year sensitivity run with specified diabatic heating.

The control run is forced by the observed climatological annual cycle of the sea surface temperatures. The sensitivity run is forced by the same external forcing as the control run, except for an intensification of the atmospheric heat rate over the WTP in the summer (JJAS) of each year. To avoid unreal atmospheric responses by excessive atmospheric heating, we set the atmospheric heating rate with respect to the vertical profile of composite difference of the WTP atmospheric heat rate (see Fig. 4d). The output in JJAS for years 21-40 is analyzed.

\section{Dominant coupled patterns between TP heating and $\mathrm{H} 200$ in the northern hemisphere}

We applied a SVD analysis for the heat source of the TP and its surrounding area $\left(20-40^{\circ} \mathrm{N}, 50-110^{\circ} \mathrm{E}\right)$ and the $\mathrm{H} 200$ in the northern hemisphere for the summers of 1980-2018. The diabatic heating over oceans is much stronger than that over land, and therefore the HS of the Indian Ocean south of $20^{\circ} \mathrm{N}$ is excluded in the SVD analysis. The signal of the heating over land is well captured. 
(a) H200 SVD1 in $1980-2018 \mathrm{SCF}=42.45 \%$ cor $=0.72$

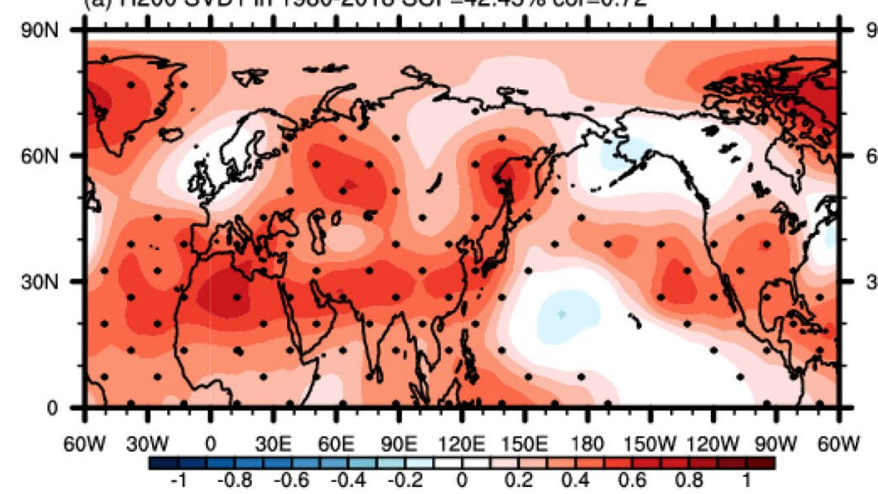

(c) Q1 SVD1 in 1980-2018

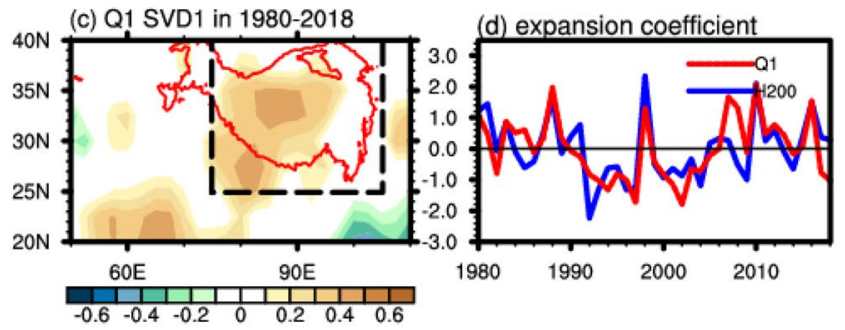

Fig. 1 (a), (c) The first SVD mode (SVD1) and (b), (e) the second SVD mode (SVD2) between the heat source over TP and its surrounding region $\left(20-40^{\circ} \mathrm{N}, 50-110^{\circ} \mathrm{E}\right)$ and $\mathrm{H} 200$ in the northern hemisphere during 1980-2018. The percentage of the squared covariance fraction (SCF) and the temporal correlation coefficient (cor) between two expansion coefficients are indicated at the top of each

The first SVD mode (SVD1) explains $42.5 \%$ of the total covariance between the two fields, with a correlation of 0.71 between the associated expansion coefficient time series (Fig. 1a, c). The pattern of the heat source features statistically significantly enhanced heating over the WTP and a small area north of the Arabian Sea. The corresponding $\mathrm{H} 200$ pattern is dominated by positive anomalies along the mid- and low-latitudes of the northern hemisphere. A zonal teleconnection pattern is embedded along the above-normal heights, with maximum anomaly centers over North Africa, west of the TP, northeastern Asia, and the west coast of America. The circumglobal teleconnection pattern of SVD1 resembles the CGT pattern (Fig. S1), which is represented here by the second EOF mode of the northern hemispheric $\mathrm{H} 200$. The corresponding principal component of the CGT pattern is therefore used as the CGT index. There are also some differences in the location and intensity of the anomaly centers. The teleconnection pattern associated with the WTP heating in SVD1 shows a clearly expanded anomaly center over North Africa and a contracted anomaly center over northeastern Asia. The positive anomaly over North Africa extends to Central America via the North Atlantic. The corresponding H200 of SVD1 is also significant in the tropics, except for a negative anomaly center over the North Pacific. The significant correlation coefficient between the time series of the two fields of SVD1 suggests a strong (b) H200 SVD2 in $1980-2018$ SCF $=17.56 \%$ cor $=0.64$

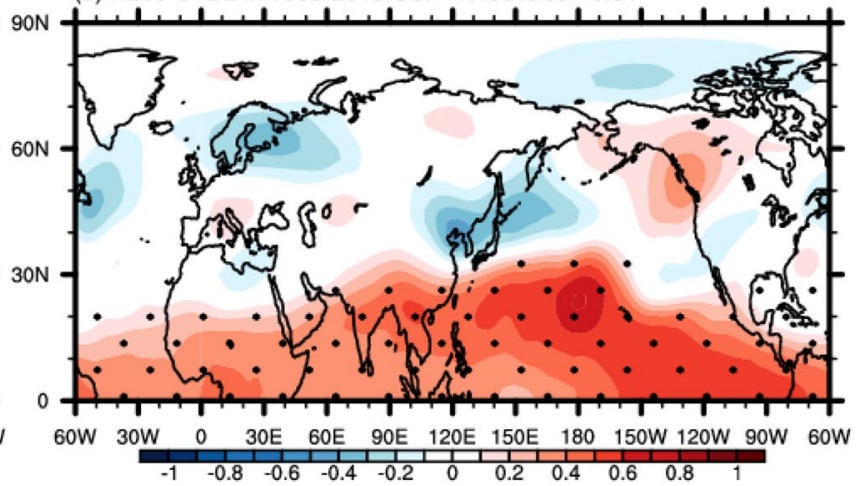

(e) Q1 SVD2 in 1980-2018

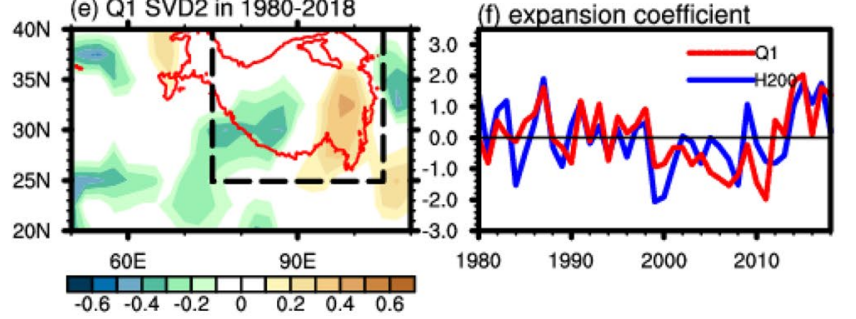

panel. The solid box corresponds to the heat source field used in the SVD analysis and the dashed box corresponds to the area of the WTP. The dotted regions denote the values that are significantly above the $95 \%$ confidence level, and only the heat source values exceeding the $95 \%$ confidence level are plotted. d, f Expansion coefficients of the heat source and H200 for SVD1 and SVD2

relationship between the WTP heat source and the CGTlike circulation pattern.

Figure 1b, e show the second SVD mode (SVD2), which explains $17.6 \%$ of the total covariance. The correlation between the associated time series is 0.56 . The SVD2 for the heat source shows a dipole anomaly pattern across the west and east of the TP. Coupled with the dipole heating pattern over the TP, the anomalous high over tropical oceans, especially the North Pacific, is significantly enhanced, indicating that the SVD2 mode is greatly influenced by the SSTA of the Pacific Ocean. There are also several negative anomaly centers in the extratropics, but no significant correlation is seen between these anomaly centers and the expansion coefficient time series of the SVD2 pattern. The SVD2 therefore implies a connection between the dipole pattern of the TP heat source and the atmospheric circulation in the tropics.

The first two dominant SVD patterns account for $>60 \%$ of the total covariance between the two fields. The WTP heat source shows a significant variation in both SVD patterns, suggesting that the WTP is the key region associated with the atmospheric circulation of the northern hemisphere. The connection between the WTP heat source and the teleconnection patterns in the northern hemisphere is therefore examined further in the following section. 


\section{Structures of the WTP heat source and its associated teleconnection patterns}

Composite analysis and linear regression analysis are used to investigate the WTP heat source anomaly and the associated circulation pattern. The $3 \mathrm{D}$ atmospheric heating rate anomaly is obtained from the composite difference between the strongly positive and negative heat source years of the WTP in summer. The 3D structure of the anomalous heating obtained from the composite difference is also used to force the numerical models. The teleconnection pattern corresponding to the heating of three components at different elevations is obtained on the basis of the regressed pattern of H200 against the time series of the regionally averaged heating.

\subsection{Composite analysis}

Figure 2 a shows the time series of the WTP-averaged anomalous heat source, from which we find the large interannual variability of the WTP heat source since the mid-1990s. The correlation coefficient between the normalized WTP heat source anomaly and the CGTI is 0.51 , which is statistically significant at the $99 \%$ confidence level. The scatter plot also shows that the CGTI was in-phase with the WTP heat source for 30 years and out-of-phase for only nine years during 1980-2018 (Fig. 2b). This feature indicates that the CGTlike zonal wave pattern associated with the WTP heat source may influence the observed CGT pattern.

To detect the 3D structure of the WTP heat source, strongly positive and negative heating years are defined as exceeding \pm 1 standard deviation. We select seven strong years and six weak years of the WTP heat source. Figure 3 displays the $3 \mathrm{D}$ structure of the heating rate anomaly calculated by the composite difference between the strong and weak WTP heating years. The vertically-integrated atmospheric heating anomaly is the strongest in the southwestern WTP and it weakens toward the northeast of the WTP. The atmospheric heating rate anomaly at the lower pressure levels follows a similar horizontal distribution (Fig. 3b). The southwestern slopes lift the heating maximum to the main body of the WTP, with an elevation $>3000$ m corresponding to the 700-hPa pressure level (Fig. 3b). This suggests the importance of ascending motion for the $\mathrm{LH}$ release forced by large-scale orography. The atmospheric heating anomaly of the main body of the WTP is stronger than that of the southeastern WTP above $500 \mathrm{hPa}$. The strong anomalous heating can extend to the upper troposphere, with a maximum $>1 \mathrm{~K} \mathrm{day}^{-1}$ from 500 to $250 \mathrm{hPa}$ in the region $30-35^{\circ} \mathrm{N}$.

The composite difference in heating along the southwestern slope of WTP is also seen in the height-longitude plot (Fig. 3c), with the maximum distribution at a longitude of $80^{\circ} \mathrm{E}$. Figure $3 \mathrm{~d}$ compares the vertical profiles of the climatological and anomalous values of WTP-averaged heating. The heating anomaly is only half that of the climatological value in the lower troposphere and the ratio increases with height. The heating anomaly in the mid-upper troposphere has the same magnitude as the climatological value and is larger than the climatological value above $150 \mathrm{hPa}$. In general, a significant heating anomaly occurs between the positive and negative heating years, especially on the southwestern slopes of the WTP and in the upper troposphere over the main body of the TP. The variability of the diabatic heating induced by ascending motion can account for this feature and the change in moisture transport caused by the ISM is also important for summer diabatic heating over the TP (Zhang et al. 2017).

Figure 3a shows the H200 associated with the WTP heat source anomaly. There exists an apparent mid-latitude teleconnection pattern and the pattern correlation coefficient between (a) WTP HS anomaly

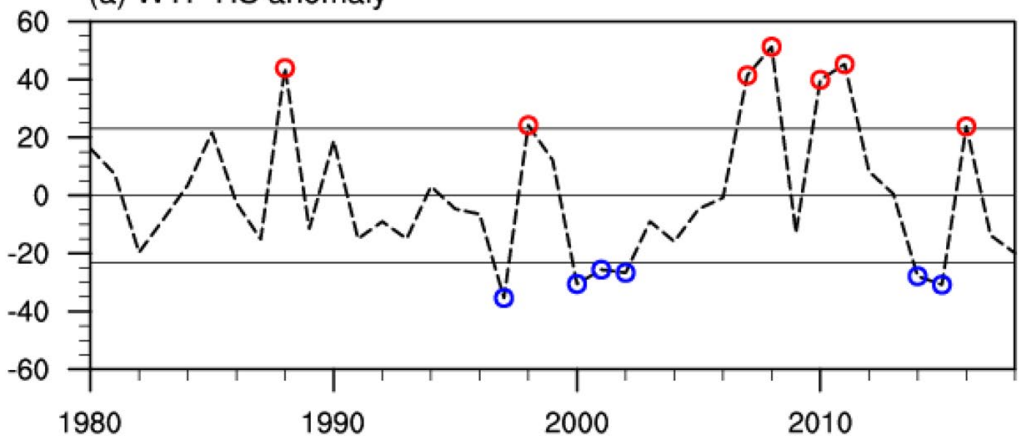

(b) CGTI\&WTPHS

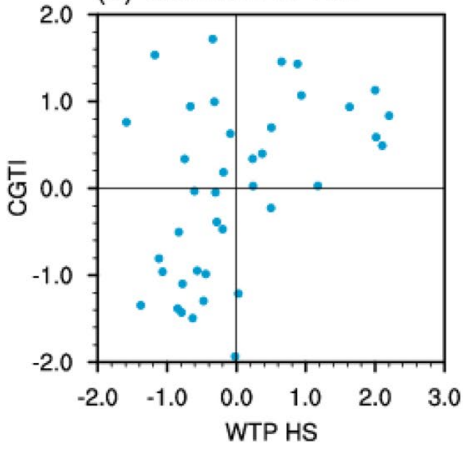

Fig. 2 a Time series of the WTP-averaged heat source $\left(\mathrm{W} \mathrm{m}^{-2}\right)$. The years with strong positive and strong negative WTP heating (stronger than \pm 1 standard deviation) are marked with red and blue circles, respectively. b Scatter plot between the normalized WTP heat source and the CGT index 
(a) H200 \& WTP HS
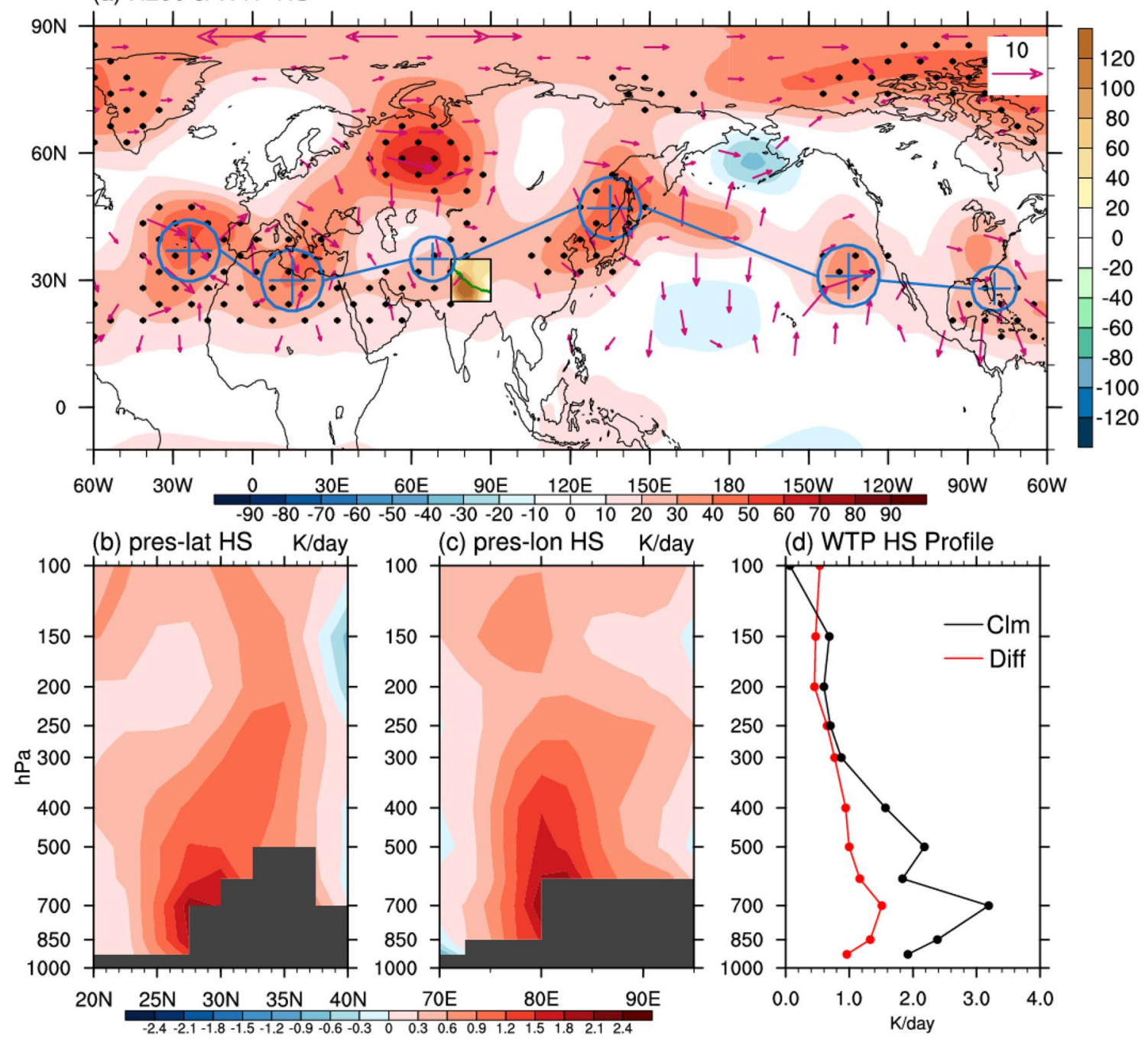

(d) WTP HS Profile

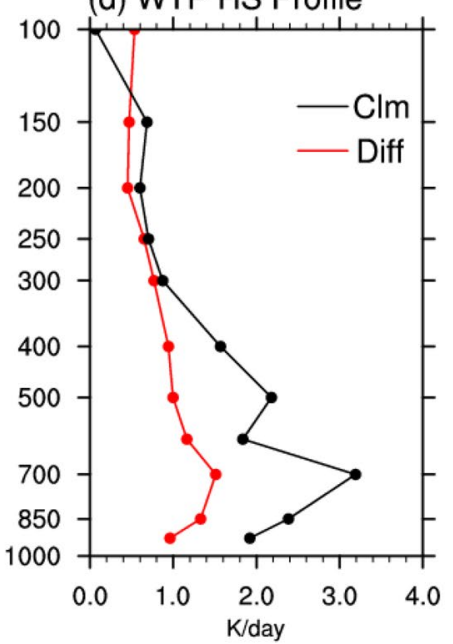

Fig. 3 a Composite differences in H200 (shading; gpm), WAF (vector; $\mathrm{m}^{2} \mathrm{~s}^{-2}$ ), and the WTP heat source (shading, black box; $\mathrm{W} \mathrm{m}^{-2}$ ). The blue circles indicate the TP-CGT centers and the blue lines denote the path of the TP-CGT pattern. The black dots denote H200 differences that are significantly above the $95 \%$ confidence level. b Pressure-latitude cross-section of the difference in WTP atmospheric heat rate $\left(\mathrm{K} \mathrm{day}^{-1}\right)$ and $\mathbf{c}$ pressure-longitude cross-section of the difference in WTP atmospheric heat rate $\left(\mathrm{K} \mathrm{day}^{-1}\right)$ between the strong positive and strong negative WTP heating years. Gray shading in parts $\mathbf{b}$ and $\mathbf{c}$ indicates the elevation of the TP (elevation $=3000 \mathrm{~m})$ in the NCEP reanalysis 2 . d Climatology (black) and composite difference (red) in the WTP-averaged atmospheric heat rate $\left(\mathrm{K} \mathrm{day}^{-1}\right)$ the teleconnection pattern and the CGT is 0.6. There are six anomalous circulation centers (significant at the $99 \%$ confident level), respectively over North Atlantic, North Africa, west of the TP, northeastern Asia, the west coast of North America, and the Gulf of Mexico. The associated wavenumber- 6 teleconnection pattern is referred to here as the TP-CGT, which features larger (smaller) anomalous centers than the CGT over west (east) of the TP.

\subsection{Teleconnection patterns associated with diabatic heating}

The TP has experienced an elevation-dependent change in climate during the last few decades. The enhanced warming is correlated with the elevation and the warming rate of the main body of the TP, which is different from that in the surrounding area (An et al. 2017; Duan and Xiao 2015; Ji et al. 
Table 1 Correlation coefficients between the time series of heat source and its three components. The three rows correspond to the average diabatic heating over the western, southwestern and main body of TP

\begin{tabular}{llll}
\hline & Sensible heat & Latent heat & $\begin{array}{l}\text { Radiative } \\
\text { conver- } \\
\text { gence }\end{array}$ \\
\hline Entire WTP & 0.14 & $0.86^{* *}$ & $0.37 *$ \\
WTP below 3000 m & -0.24 & $0.79^{* *}$ & $0.52^{* *}$ \\
WTP above 3000 m & $0.38^{*}$ & $0.85^{* *}$ & 0.04 \\
\hline
\end{tabular}

2020; Lin et al. 2013; Qin et al. 2009). We divide the WTP into two parts: the main body (elevation $>3000 \mathrm{~m}$, north of the green line in Fig. 3a) and the southwestern part of the
WTP (elevation $<3000 \mathrm{~m}$, south of the green line in Fig. 3a). Table 1 shows the correlation coefficients between the heat source and the different components of heating. The heat source is highly correlated with the latent heat over the entire WTP, which indicates $a>74 \%$ contribution to the WTP heat source from the latent heat release. The SSHF is negatively correlated with the heat source in the main body of the WTP $(-0.24)$ and significantly correlated with the heat source below $3000 \mathrm{~m}$ (0.38). By contrast, the correlation coefficient between radiative heating and the heat source is 0.52 above $3000 \mathrm{~m}$, but only 0.04 in the southwestern WTP, where the elevation is $<3000 \mathrm{~m}$.

To investigate the circulation patterns associated with the different amounts of diabatic heating, Fig. 4 shows the maps of $\mathrm{H} 200$ regressed onto the time series of different (a) WTP HS Reg

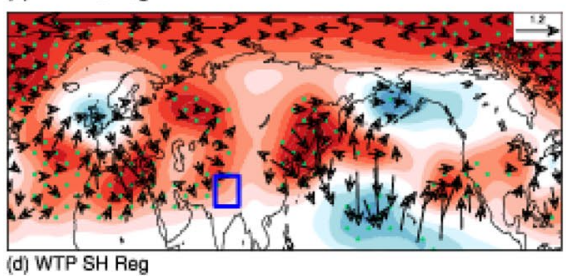

(b) HS\&3000 Reg

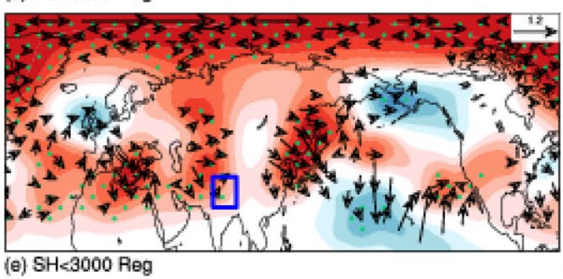

(c) HS $>3000$ Reg

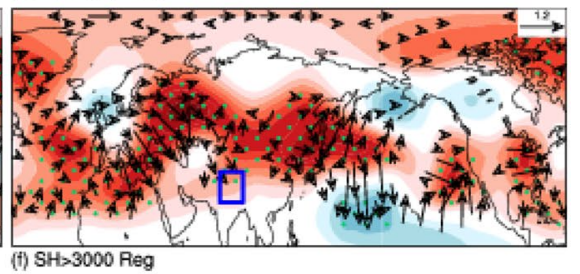

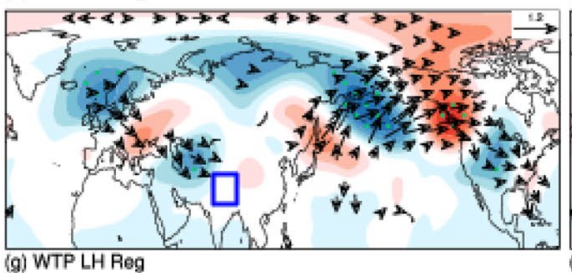
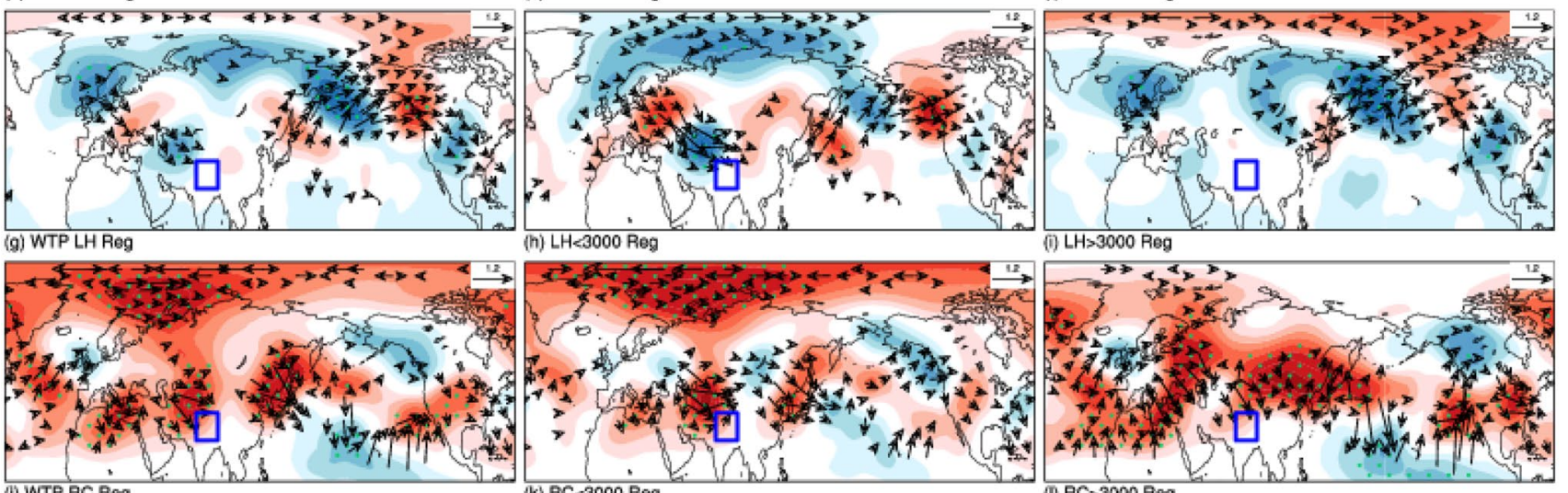

(h) LH<3000 Reg

(i) LH $>3000$ Reg
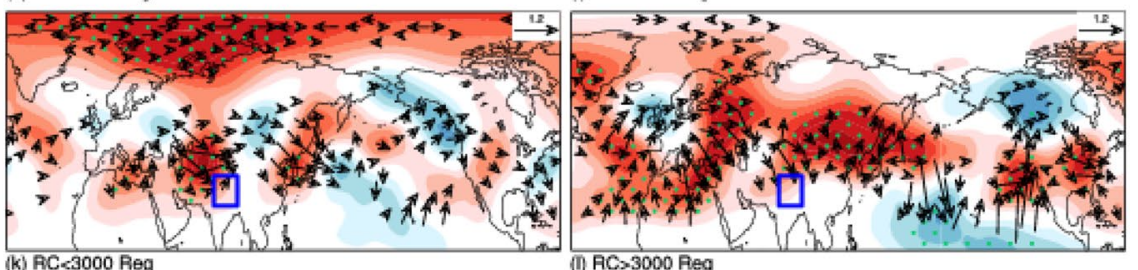

0) WTP AC Reg

(k) RC $<3000$ Reg

(1) ACs 3000 Reg
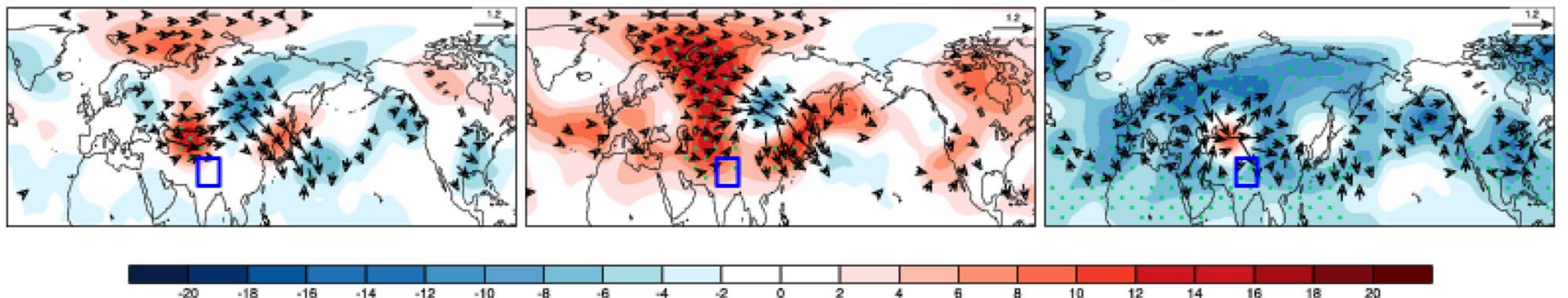

Fig. 4 Regressions of H200 (shading; m) and associated wave activity flux (vector; $\mathrm{m}^{2} \mathrm{~s}^{-2}$ ) on the standardized time series of (a) the heat source averaged over the WTP, (b) the heat source averaged over the southwestern WTP (elevation $<3000 \mathrm{~m}$ ), and (c) the heat source averaged over the main body of the WTP (elevation $>3000 \mathrm{~m}$ ). Regressions of H200 and associated wave activity flux on the standardized time series of (d) the SSHF averaged over the WTP, (e) the SSHF averaged over the southwestern WTP (elevation $<3000 \mathrm{~m}$ ), and (f) the SSHF averaged over the main body of the WTP (elevation $>3000 \mathrm{~m}$ ). Regressions of H200 on the standardized time series of (g) the latent heat averaged over the WTP, (h) the latent heat averaged over the southwestern WTP (elevation $<3000 \mathrm{~m}$ ), and (i) the latent heat averaged over the main body of the WTP (elevation $>3000 \mathrm{~m}$ ). Regressions of H200 and associated wave activity flux on the standardized time series of $(\mathbf{j})$ the radiation heating component averaged over the WTP, (k) the radiation heating component averaged over the southwestern WTP (elevation $<3000 \mathrm{~m}$ ), and (l) the radiation heating component averaged over the main body of the WTP (elevation $>3000 \mathrm{~m}$ ). Contour intervals are $2 \mathrm{gpm}$. The black dots denote the $\mathrm{H} 200$ that is significantly above the $95 \%$ confidence level 
amounts of diabatic heating and associated WAF. It is seen that active propagation of WAF occurs over the western TP. Corresponding to the strong atmospheric heating of the WTP, the positive phase of the TP-CGT pattern appears in the northern hemisphere, and the TP-CGT pattern is associated with the WTP heat source in both regressed maps. The heat source of the southwestern WTP shows an apparent relationship with the local circulation, although the highelevation heating and mid-latitude circulation of remote areas are more closely linked. The low-elevation heating of the WTP also shows a significant relationship with the polar circulation, which is in contrast with the heating over the main body of the WTP.

We decompose the contributions of the three heating components to $\mathrm{H} 200$ and find that the $\mathrm{H} 200$ associated with surface sensible heating is characterized by a high-latitude wave train. The wave-activity flux analysis (Fig. 4) shows that a high-latitude wave train associated with sensible heating propagates from North Japan to central North America through the Bering Sea and Canada. In addition, the strong SSHF is accompanied by a wave train originated over the Norwegian Sea that propagates to the northwest of the WTP. The WTP heat source is mainly contributed by latent heat, so the corresponding anomalous patterns show a similarity between the heat source and latent heat as expected. The radiative components over different areas correspond to very distinct circulation patterns. The distribution of $200-\mathrm{hPa}$ height anomalies associated with the WTP-average radiative heating features a wavenumber- 4 wave train over Eurasia (Fig. 4j). The low-elevation radiative heating corresponds to a significantly reversed T-shaped circulation anomaly along $70^{\circ} \mathrm{N}$, the above-normal height anomaly is stronger than former, and the wave train over Eurasia is still apparent. However, the atmospheric circulation associated with the radiative heating of the main body shows a below-normal anomaly in the northern hemisphere, except to the west of the TP. There are differences in the underlying characteristics of the cloud cover, snow cover, and atmospheric humidity between different elevations (An et al. 2016, 2017; Yao 2012, 2019). The cooling effect of atmospheric radiation is stronger over the main body of the WTP than over the surroundings as a result of the high elevation. All these factors may result in the contrasting circulation anomalies associated with radiative heating at different elevations.

The local anomalous center over the west of the WTP is significantly associated with the heating over the low attitudes (Fig. 4c, f, i, 1). However, the circulation pattern associated with heating of high elevation shows a weaker anomalous center around the WTP (Fig. 4b, e, h, k). We suggest that the northwest-southeast orientation of the Himalaya restricts the eastward propagation of diabatic heat energy and that the local circulation anomaly is first formed by strong atmospheric heating and then tends to propagate meridionally. The mid-upper tropospheric heat uplifted by the main body of the WTP can propagate to remote areas via the Rossby wave response along the westerly jet stream. The combination of different latent heat anomalies at different elevations results in the overall above-normal TP-CGT.

\section{Physical mechanisms for the TP-CGT}

Not all regions around the TP correspond to the TP-CGT pattern, and the high-elevation heating of the WTP shows stronger links with the circulation anomalies in remote areas. Previous studies have documented that the ISM rainfall plays an important role in the maintenance of the CGT (Ding and Wang 2005, 2007; Ding et al. 2011). The southwestern WTP is geographically proximal to the ISM, but shows a weaker connection to the CGT. This suggests that the TPCGT is induced by the high-elevation heating. We present here observational and modeling evidence to confirm this speculation.

\subsection{The two-direction structure of the TP-CGT pattern}

Previous studies have shown that the remote diabatic heating in the Asian monsoon region can induce different Rossby wave response depending on the latitude. Kelvin waves emanate via equatorial heating and create extensive high-level easterly winds to the east. By contrast, a Gill-type Rossby wave response is induced by heating over the Indian Peninsula, which is called monsoon-desert mechanism. The Gilltype Rossby wave interacts with the westerly jet stream and affects the vertical motion over the Sahara Desert (Gill 1980; Rodwell and Hoskins 1996; Yang et al. 1992). The region of the TP-CGT from the WTP to the east coast of North America resembles this Gill-type Rossby wave response, which is similar to the results reported by Lu et al. (2018). The midlatitude diabatic heating can excite stationary Rossby waves trapped on the westerly jet stream (Hoskins and Ambrizzi 1993; Yasui and Watanabe 2010). We suggest that the TPCGT is composed of two parts: a westward Rossby wave response and an eastward-propagating wave train along the westerly jet stream.

Figure 5 shows the circulation anomalies associated with the TP-CGT. The circulation centers are dominated by significant anticyclonic wind anomalies at $200 \mathrm{hPa}$, accompanied by an upper-tropospheric divergence and a lowertropospheric convergence, favoring enhanced precipitation. A strong TP-CGT is also associated with a circumglobal easterly wind anomaly along the boundary line between the climatological easterly and westerly winds, which may conduce the anticyclonic wind anomaly of the teleconnection centers. The precipitation in the center of the TP-CGT 
(a) Div200\&UV200

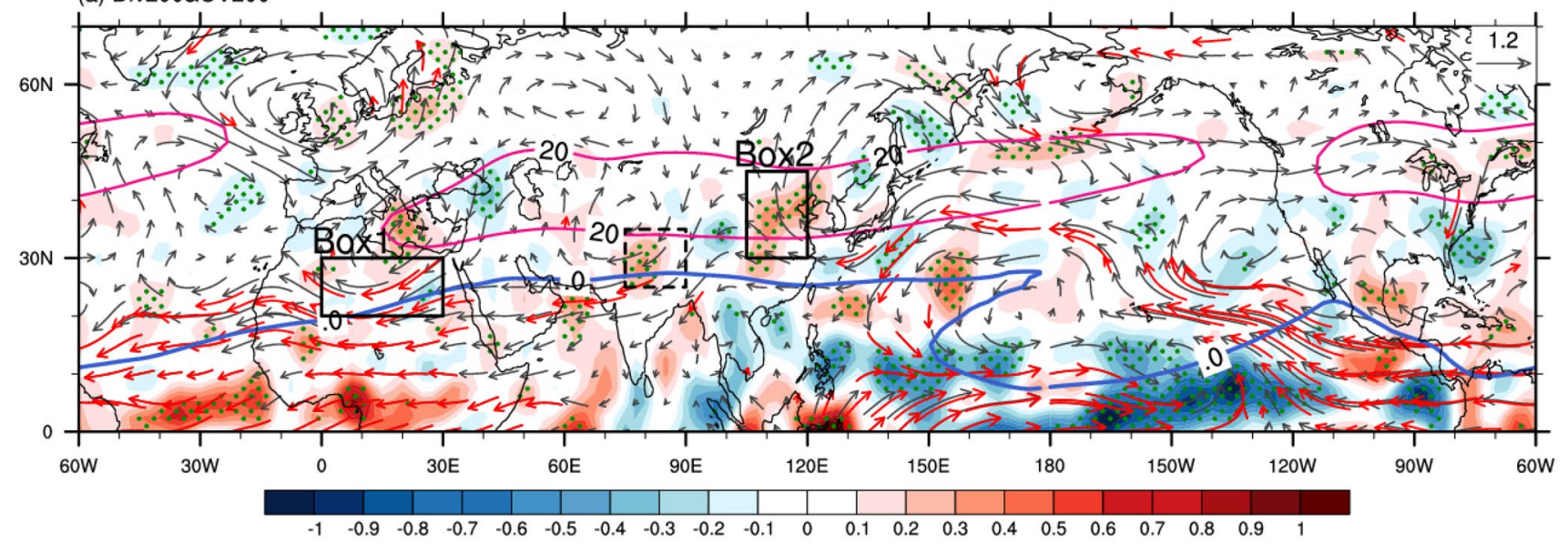

(b) Prec\&UV850

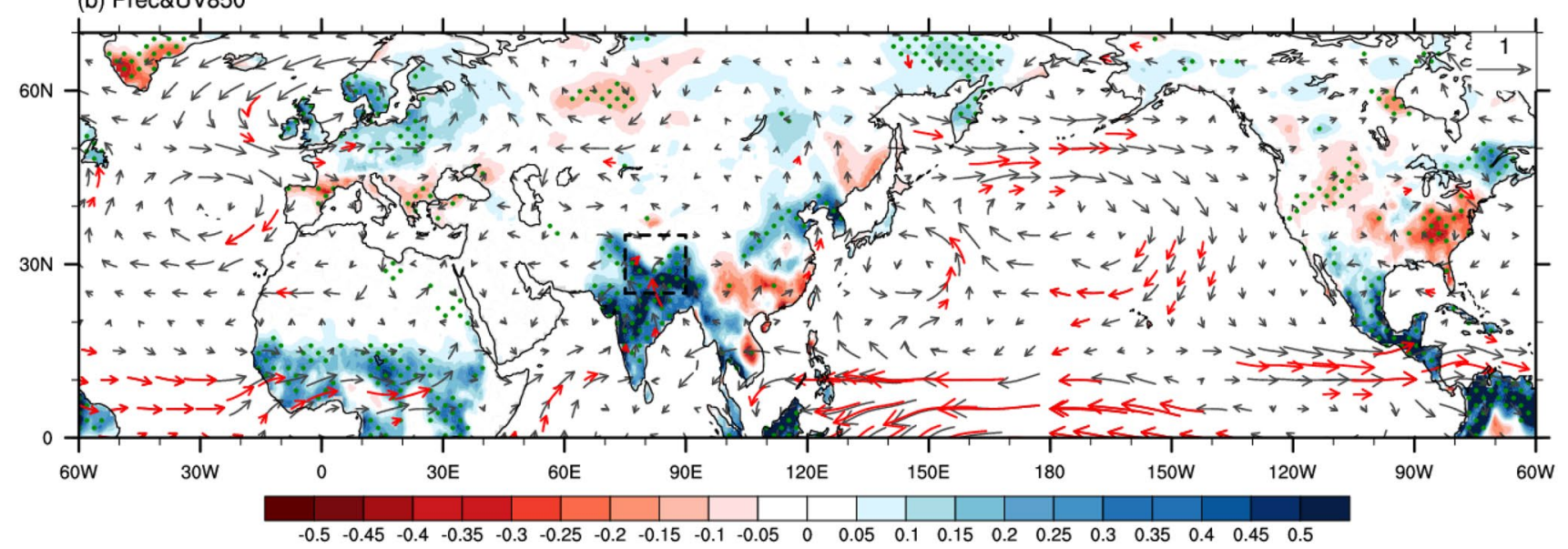

Fig. 5 Regressions of (a) the 200-hPa wind divergence (shading; $\mathrm{s}^{-1}$ ) and wind vectors (arrows; $\mathrm{m} \mathrm{s}^{-1}$ ), (b) precipitation (shading; $\mathrm{mm}$ $\mathrm{day}^{-1}$ ) and $850-\mathrm{hPa}$ wind vectors (arrows; $\mathrm{m} \mathrm{s}^{-1}$ ) on the time series of the WTP heat source. The green dots denote that the 200-hPa wind divergence in part (a) and the precipitation in part (b) are signifi-

is also significantly enhanced, indicating that WTP heating can affect precipitation in remote areas via the circulation anomaly of the TP-CGT. The WTP heat source is positively correlated with the precipitation in the whole Indian Peninsula, which shows an interaction between WTP and ISM heating, as pointed by Jiang and Ting $(2017,2019)$. To separate the different roles played by the western TP heat source dominated by latent heating and by the Indian monsoon heating, Fig. S2 shows partial regression maps of ISM (the core monsoon zone, $18-25^{\circ} \mathrm{N}, 75-85^{\circ} \mathrm{E}$ ) (Gadgil 2003; Jiang and Ting 2017) and WTP latent heating on the H200. The circulation pattern associated with WTP heating after removing the impact of ISM resembles the TP-CGT pattern, but the pattern is not obvious conversely. The result shows that the TP-CGT pattern is sensitive to the location of the heating, and the WTP heating is more effective than the ISM heating in inducing the teleconnection pattern. cantly above the $95 \%$ confidence level. The pink contours in part (a) denote the westerly jet stream $>20 \mathrm{~m} \mathrm{~s}^{-1}$ and the blue contour depicts the zonal wind equal to 0 . The red vectors denote that the values of either zonal or the meridional wind component is significantly above the $95 \%$ confidence level

To verify the process by which the WTP heat source excites the two-direction structure of the TP-CGT, a running lead-lag correlation is performed between the WTP heat source anomaly and the height anomaly of the two neighboring TP-CGT centers (over North Africa and northeastern Asia, corresponding to Box 1 and Box 2 in Fig. 5a, respectively). Because the propagation of the Rossby wave may be hardly captured on a monthly scale, the daily H200 anomaly from May 12 to October 20 and the daily WTP heat source in summer (JJAS) during the time period 1980-2018 are used in our calculations. For example, we calculate the correlation coefficients between the 39-year time series of the WTP heat source on June 1 and the Box 1 height anomalies from May 12 to June 20 to obtain a total of 41 correlation coefficients from lag -20 to +20 days. The WTP heat source occurs from June 1 to September 30 and this calculation is implemented on a daily basis. The results are shown in Fig. 6 
Fig. 6 Running lead-lag correlation between the daily WTP heat source and $\mathrm{H} 200$ in the TPCGT center of (a) North Africa and (b) Southeast Asia. The ordinate is the date from June 1 to September 30. The abscissa is the days on which the WTP heat source leads $\mathrm{H} 200$ at the TP-CGT center. The black dots denote the correlation coefficients are significantly above the $95 \%$ confidence level

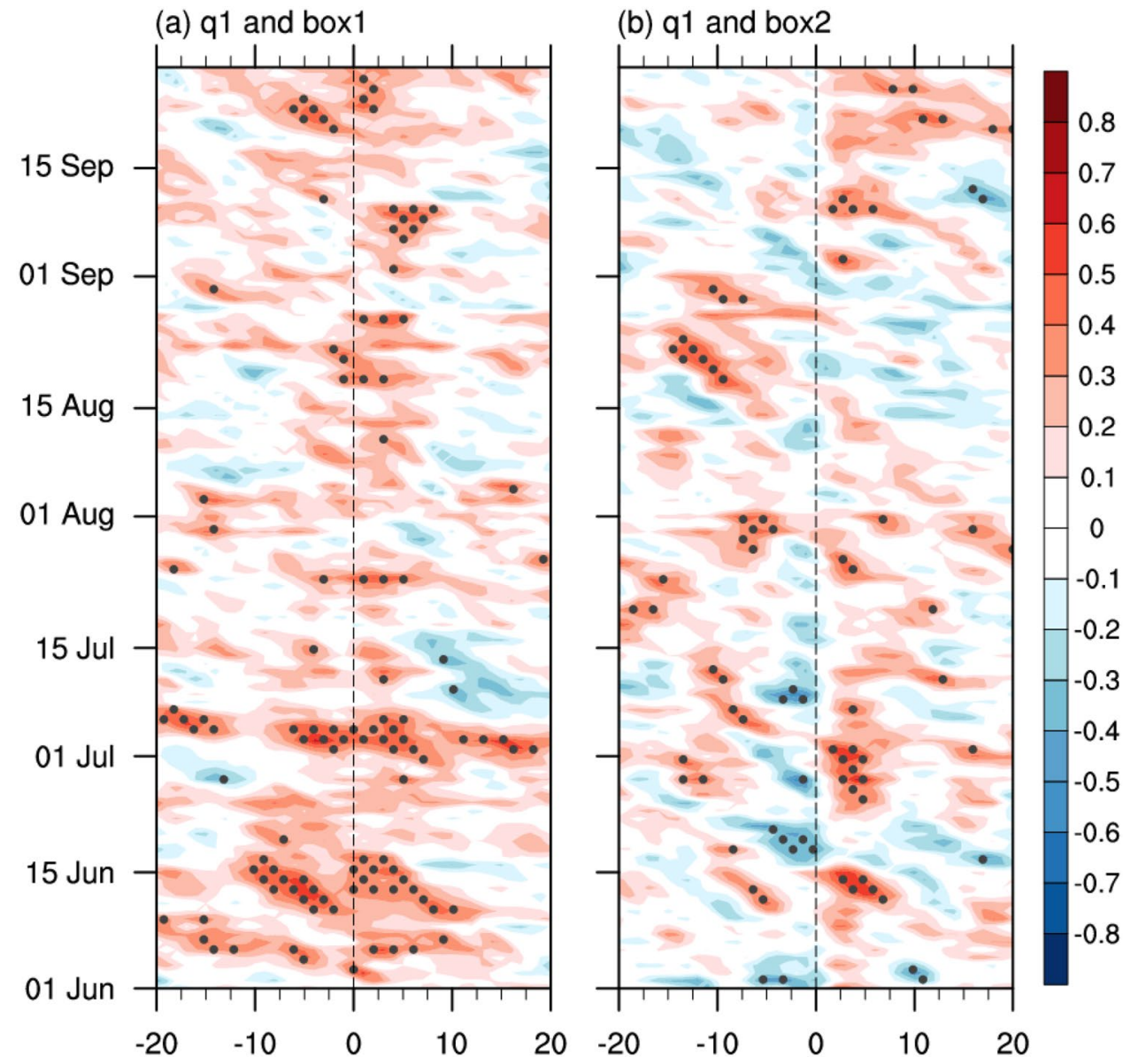

with an abscissa of lag days and an ordinate of the calculated date of the WTP heat source.

The increase in the height over North Africa is significantly correlated with the WTP heat source from lag 0 to +8 days during early June and early July. This connection is weak from late July to mid-August, but then increases later again. The preceding height anomaly over North Africa also shows a significant correlation with the WTP heat source, indicating an upstream effect of the circulation anomaly that propagates along the westerly jet stream. The height anomaly of northeastern Asia exhibits a significant and positive relationship with the WTP heat source from lag +1 to +8 days. This linkage is stable before mid-July and after September. The WTP heat source leads the two neighboring TP-CGT centers by 1-8 days, suggesting a two-direction propagation of the Rossby wave response from the WTP.

It is interesting that the westward atmospheric response is more unstable than the eastward one. The center of TPCGT over northeastern Asia is weaker in August than in the other months (figure not shown). We consider that the change in the westerly jet stream results in this instable relationship during summer. The configuration of the jet stream determines the meridional location and wavenumber of the wave train. The westerly jet features a transient latitudinal migration (Schiemann et al. 2009), which accounts for the unstable correlation when we take a fixed region as the center of the TP-CGT. Since the CGT also shows large interseasonal variability (Ding and Wang 2007), it is hard to capture a dynamic teleconnection center. Numerical models are therefore used to better understand the TP-CGT.

\subsection{Simulations of numerical models}

Figure 7 shows the response of the 200-hPa geopotential height to the WTP anomalous heating based on an experiment with a simple linearized model (LBM) forced by the composite difference in the WTP heat source. An anomalous high occurs over the WTP on the fifth day after the start of model integration, which corresponds to the TP-CGT center over the west of the WTP. The teleconnection patterns appear after the model is integrated for 10 days and continuously strengthen to form a circumglobal positive height anomaly. The experimental results validate the observationbased conclusions that the WTP heating anomaly can induce the TP-CGT pattern, which leads the TP-CGT centers in North Africa and northeastern Asia by 1-8 days.

The diabatic heating in the AGCM is represented by a series of parameterization schemes that include clouds, 
(a) H200\&UV200 day5

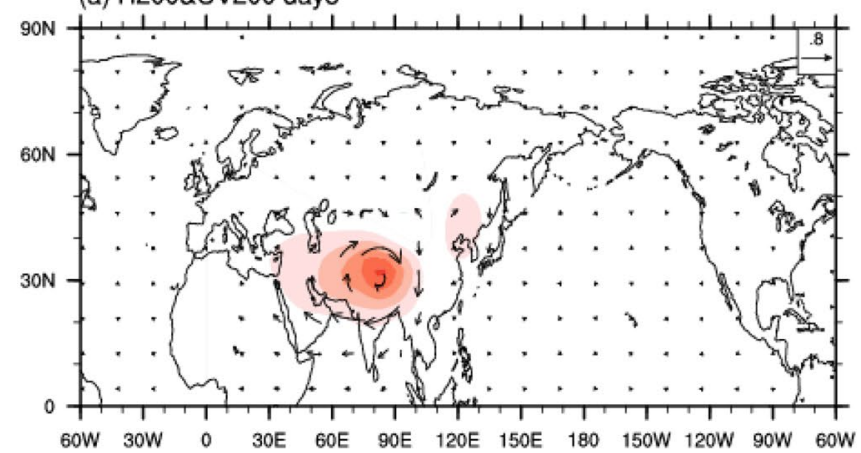

(c) H200\&UV200 day15

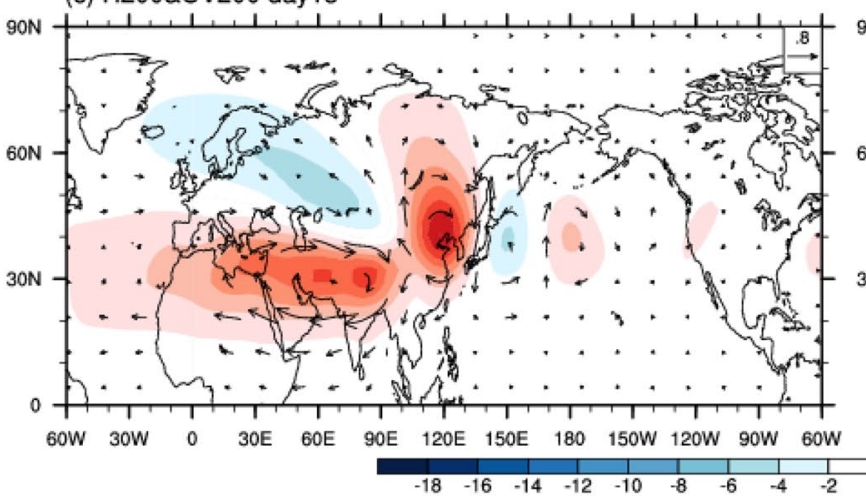

(b) H200\&UV200 day 10

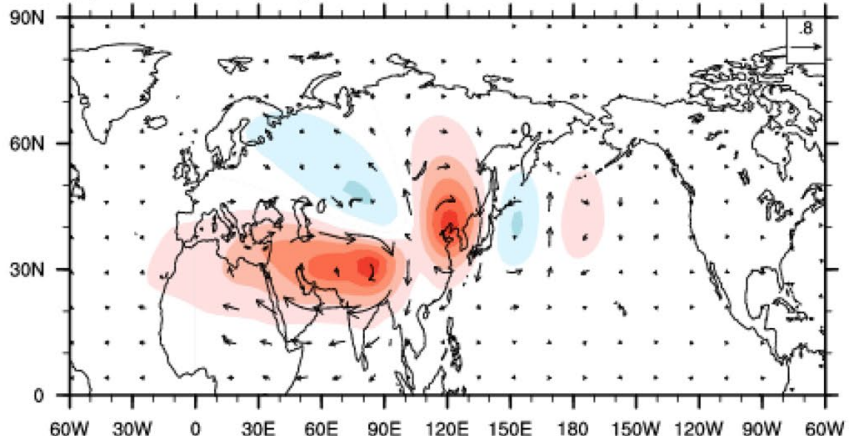

(d) H200\&UV200 day26-30

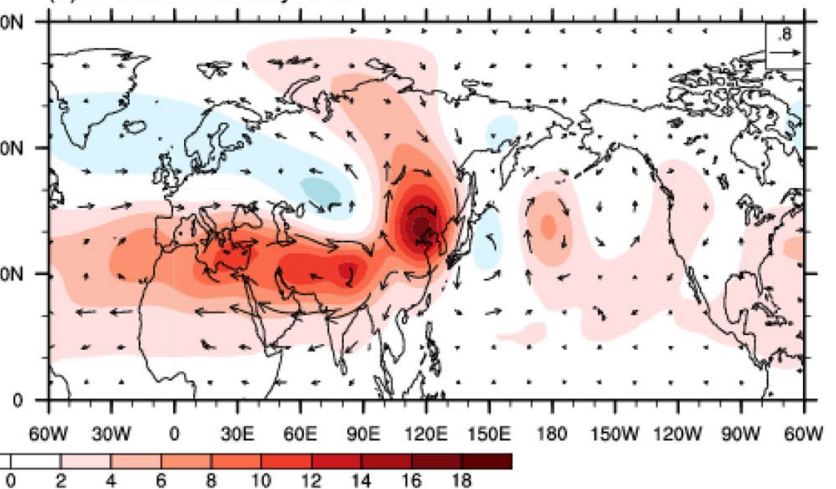

Fig. 7 The 200-hPa height (shading; gpm) and wind (arrows; m $\mathrm{s}^{-1}$ ) response of (a) day 5, (b) day 10, (c) day 15, and (d) average to the prescribed heat forcing over the WTP from day 26 to day 30 .

radiation, and turbulence. The unrealistic atmospheric heating anomaly used in the model may result in large errors. To ensure a real atmospheric response, we calculate the heating ratio profile of the climatological heating to the anomalous heating over the WTP by referring to the method of Li et al. (2016) and then multiply the atmospheric heating rate by the heating ratio profile in each time step when the model is integrated. Figure 4 shows that SSTAs may influence the TP-CGT and therefore the SST of the AGCM is fixed by the climatological SST to exclude the impact of SSTAs.

The AGCM can well reproduce the above-normal TPCGT when the WTP heat source is intensified. Figure S3 shows the third EOF mode (EOF3) of H200 in two experiments of the AGCM model. The EOF3 of control run resembles the CGT-like pattern, and features six anomalous high centers along the mid-latitudes of the northern hemisphere, which accounts for $12.96 \%$ of the total variance. The percentage of variance of the EOF3 rises to $15.76 \%$ in the sensitivity run, and the upper-level anticyclone over North Africa is also enhanced (Fig. S3b). Figure 8 shows the circulation anomaly associated with anomalous heating in the AGCM simulation and observations. The anomalous height belt along the mid-latitude is similar to the observation. It is worth noting that the difference between the control and sensitivity runs includes all the circulation anomalies induced
The background mean state used in the LBM model experiments is taken from the summer mean (JJAS) climatology for the time period of 1980-2018

by the heating of the WTP, and the most remarkable phenomenon is the in-phase TP-CGT pattern. Other characteristics are also represented in the simulations, including the easterly anomaly in the south of the TP-CGT center and the quasi-barotropic structure in most cells, except for a baroclinic circulation around the TP.

Other factors may also account for the difference between model and observation. The westerly jet stream simulated by the AGCM in both control and sensitivity runs is stronger than the observed (not shown) and the zonal asymmetry of the jet stream also differs from the observation, which account for the meridional displacement of the western hemispheric TP-CGT in the AGCM simulation. Secondly, the observed SSTA in the North Pacific acts on an anomalous anticyclone in the upper troposphere and an anomalous high at $850 \mathrm{hPa}$ (Fig. 8b, d), corresponding to strong WTP heating. When the role of the SSTA is excluded in the AGCM, no circulation anomaly occurs over the tropical ocean. In spite of these differences, the consistence between the observations and the AGCM simulation indicates that the variability in the WTP diabatic heating largely contributes to the TP-CGT teleconnection pattern during summer.

Figure 9 shows the 200-hPa barotropic energy conversion associated with the above-normal TP-CGT pattern. The barotropic energy conversion is concentrated along the both 

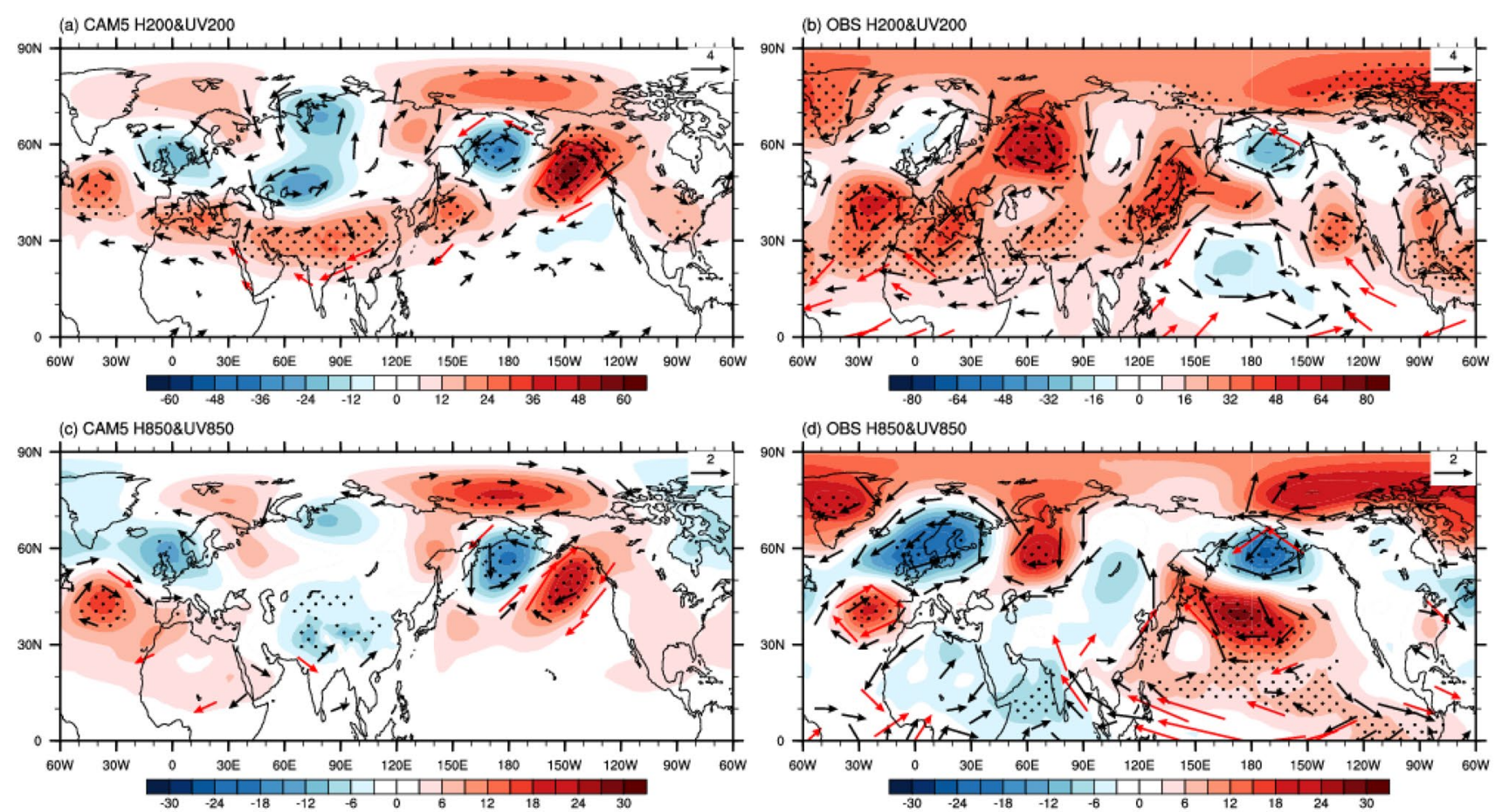

Fig. 8 Differences in (a) the 200-hPa height (shading; gpm) and wind vectors (arrows; $\mathrm{m} \mathrm{s}^{-1}$ ) and (c) the $850-\mathrm{hPa}$ height (shading; gpm) and wind vectors (arrows; $\mathrm{m} \mathrm{s}^{-1}$ ) between the sensitivity and control experiments of the AGCM. Composite differences in (b) the 200$\mathrm{hPa}$ height (shading; gpm) and wind vectors (arrows; $\mathrm{m} \mathrm{s}^{-1}$ ) and (d) the 850 -hPa height (shading; gpm) and wind vectors (arrows; $\mathrm{m} \mathrm{s}^{-1}$ )

flanks of the summer westerly jet stream. The strong WTP heating corresponds to the conversion of kinetic energy between the TP-CGT and the summer climatological mean flow around teleconnection centers. The CK is mainly contributed by the meridional shear term $\left(\mathrm{CK}_{\mathrm{y}}\right)$, as shown by the strong meridional component of the EP flux (Fig. 9e, f). The associated $\mathrm{CK}_{\mathrm{x}}$ is significantly positive on the southern flank of the exit of the Asian jet (Fig. 9c, d), indicating the intensified extraction of kinetic energy associated with the zonally elongated variations of the westerly jet stream. Despite some differences in the location of the anomalous energy conversion centers, the AGCM experimental results resemble the observed, indicating that interactions between the TP-CGT and the basic flow is intensified by the WTP anomalous heating.

There exist some differences between the model simulations and observations. For example, the negative height anomalies over the mid-latitudes of Eurasia only appear in the model simulations. Previous studies have also noticed that the negative height anomalies over Eurasia are accompanied by the CGT pattern in the AGCM model when modifying the diabatic heating by changing the surface albedo over the Indian monsoon heat low region (Saeed et al., 2011; their Fig. 1c). However, Lin et al. (2017a) could not reproduce between the years of strong positive and strong negative WTP heating in the observational dataset. The black dots denote the values of $\mathrm{H} 200$ and $\mathrm{H} 850$ that are significantly above the $95 \%$ confidence level. The red vectors denote the values of either the zonal or the meridional wind component significantly above the $95 \%$ confidence level

the negative height anomalies in a LBM model, and thus suggested that the different response among the models be caused by the extra mid-latitude precipitation induced surface albedo around the ISM region. Our LBM results resemble the response of AGCM model in Saeed et al. (2011), which may deemphasize the effect of precipitation because the LBM is a dry atmospheric model without moist process. However, the phenomenon cannot be captured in observations, and the reason is still unclear.

\section{Uniqueness of the WTP heating}

Previous studies have indicated that mid-latitude heating can induce a CGT-like response along the westerly jet stream (Yasui and Watanabe 2010), and the SVD analysis in our study suggests a specific effect of WTP heating on the TPCGT pattern. The CGT pattern is also recognized as an internal dynamic mode trapped in the westerly jet stream (Ding et al. 2011; Kosaka et al. 2009). The CGT in observations is a combination of both the internal dynamical mode and the diabatic heating induced wave response, which causes difficulties to evaluate the contribution of each component to the observed CGT pattern. The correlation between the WTP 

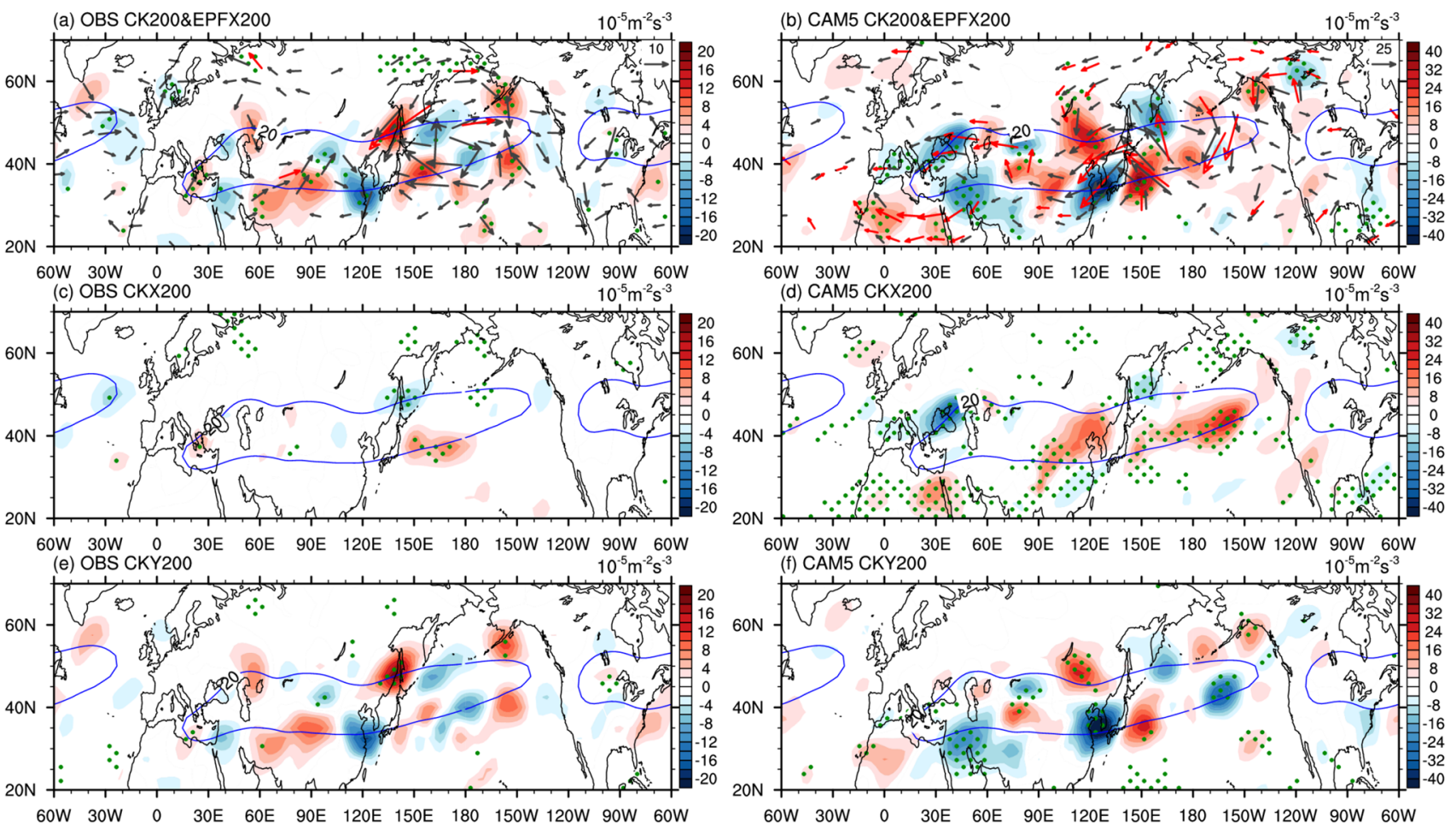

Fig. 9 Regressions of (a) CK (shading; $10^{-5} \mathrm{~m}^{-2} \mathrm{~s}^{-3}$ ) and the extended EP flux (arrows; $\mathrm{m}^{2} \mathrm{~s}^{-2}$ ), (c) $\mathrm{CK}_{\mathrm{x}}$ and (e) $\mathrm{CK}_{\mathrm{y}}$ at $200-\mathrm{hPa}$ on the standardized time series of the WTP heat source in the observational dataset from 1980 to 2018. Differences in (b) CK (shading;

heat source and the CGT pattern is 0.56 , which indicates that the TP-CGT contributes $31 \%$ of the CGT variability. However, because there are notable differences in the spatial distribution of the CGT-like patterns associated with different mechanisms, the determination coefficients (the square of correlation coefficient) are not precise enough to represent the contribution of a specific region to the CGT. We use a "regression-out" method, which evaluates the contribution of one grid to a circulation pattern by removing the impact of the gird and calculating the change in this circulation pattern, to further detect the role of mid-latitude diabatic heating in the CGT pattern.

The regression-out method is carried out as follows. First, we calculate the $\mathrm{H} 200$ anomaly associated with the latent heat release of one grid point and then compute the residual H200 field by subtracting the anomalous height from the original height field. Secondly, an EOF analysis is performed on the residual height field and the percentage variance of the EOF2 is noted. The contribution of this grid point is represented by the differences in the percentage variance between the residual and original EOF modes. This process is completed in each grid point over Eurasia $\left(5-70^{\circ} \mathrm{N}\right.$, $\left.10-140^{\circ} \mathrm{E}\right)$.

Figure 10a shows the contribution of diabatic heating over Eurasia to the EOF2 mode, which represents the CGT

$10^{-5} \mathrm{~m}^{-2} \mathrm{~s}^{-3}$ ) and the extended EP flux (arrows; $\mathrm{m}^{2} \mathrm{~s}^{-2}$ ), (d) $\mathrm{CK}_{\mathrm{x}}$ and (f) $\mathrm{CK}_{\mathrm{y}}$ at $200-\mathrm{hPa}$ between the sensitivity and control experiments of the AGCM, respectively. The blue contours denote the westerly jet stream exceeding $20 \mathrm{~m} \mathrm{~s}^{-1}$

pattern. Three key regions associated with the CGT pattern are found in southern Europe, the WTP, and northeastern Asia. The contributions of the three regions are above $26 \%$, $18 \%$, and $14 \%$, respectively. Previous studies have shown that the rainfall in southern Europe exerts a strong downstream effect on the Eurasian part of the CGT and explains $60 \%$ of the total CGT-like response to the mid-latitude diabatic heating in a LBM model simulation (Lin et al. 2017a; Yasui and Watanabe 2010). However, the steady response forced by southern European heating is concentrated in Eurasia, which differs from the circumglobal influence of the WTP heat source (Lin et al. 2017a). This also corroborates the decreasing contribution of southern European heating to the CGT in the entire northern hemisphere.

The three components of the atmospheric heat source show pronounced differences in their relationship with the CGT pattern (Fig. 10b-d). The connection between the CGT and the SSHF or latent heat is weak in southern Europe, but radiative heating makes a similar contribution to the CGT as the heat source, which suggests that the contribution of the heat source to the CGT pattern in this region is dominated by the net radiative heating in the atmosphere. The latent heat process over the WTP mainly contributes to the connection between the WTP heating and the CGT pattern, whereas the contributions of the other two heating components are 

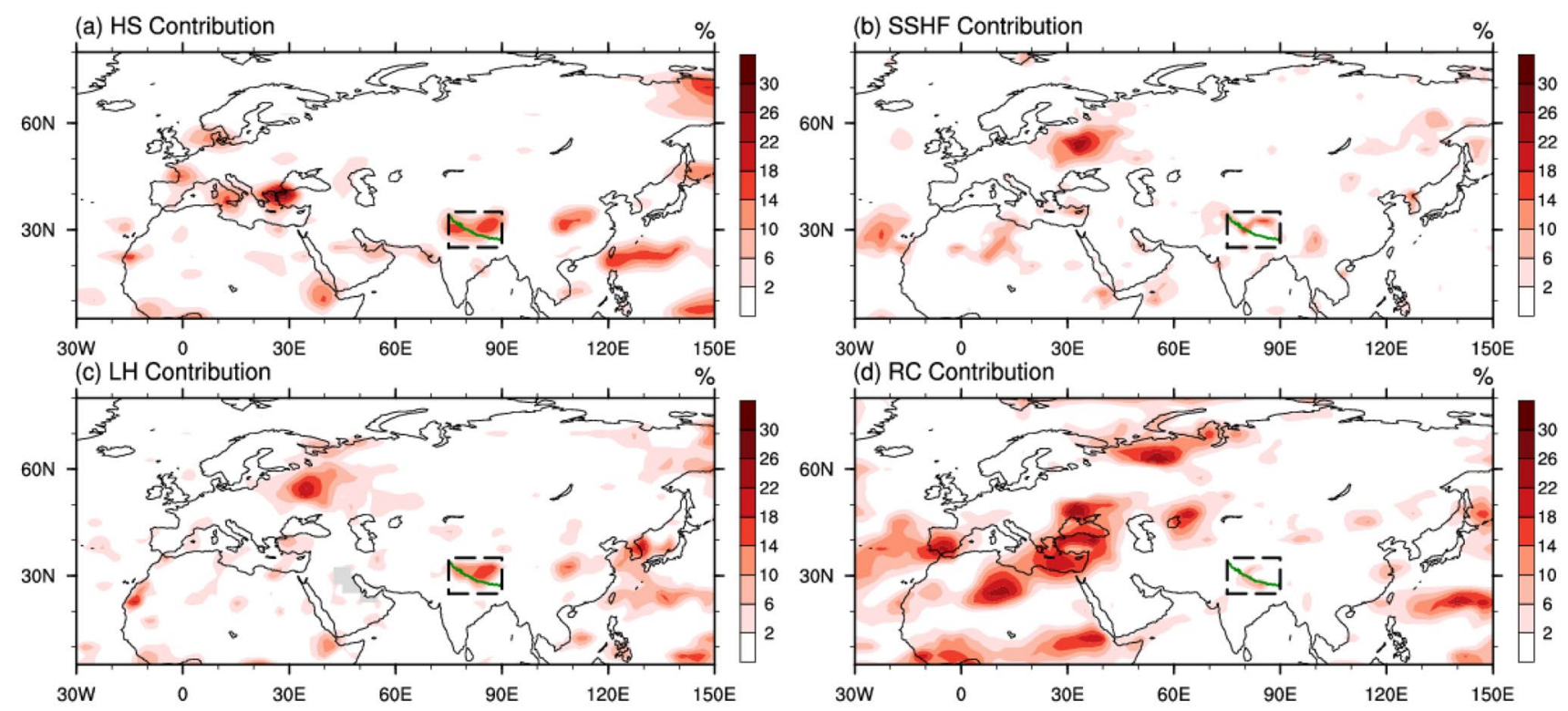

Fig. 10 Contributions (\%) to the CGT pattern by the (a) diabatic heating, (b) SSHF, (c) latent heat and (d) radiative convergence over Eurasia calculated by the regression-out method. The dashed box denotes

the WTP region. The green dashed line divides the WTP by the topographic height of $3000 \mathrm{~m}$, with the main body north of the green line and the southwestern part south of the green line

minimal. A similar magnitude of the contribution to the CGT pattern is found between the SSHF and latent heat over northern Europe, but the local atmospheric heating does not make a significant contribution to the CGT. The SSHF and LH feature an out-of-phase variation over northern Europe, with a correlation coefficient of -0.92 between the two heating components over northern Europe, which accounts for the out-of-phase association. Figure 10 shows a broader association between radiative heating and the CGT pattern over North Africa, the Mediterranean Sea, and southern Europe, which can be explained by the westward propagation of the Rossby wave from the TP and ISM region (Yang et al. 1992; Rodwell and Hoskins 1996; He et al. 2017; Lu et al. 2018, 2019). This suggests the critical upstream influence of the TP and ISM diabatic heating on North Africa via the propagation of the Gill-type Rossby wave.

The regression-out method implies a relationship between the mid-latitude diabatic heating and the CGT pattern, and we therefore discuss the contributions of the different heating components. As a result of this interaction, the anomalous heat source can be formed by the circulation anomaly of the CGT. We have verified the TP-CGT response induced by the WTP heating, although there is still uncertainty in the causal linkage between the atmospheric heating over other regions and the CGT pattern. Figure 11 shows the steady responses to different areas of heating in the LBM model. The heating pattern is obtained by the composite difference between the strong positive and negative heating years in the prescribed region, which is similar to the calculation of anomalous heating in the WTP. There are five experiments

forced by diabatic heating in five regions, including two ISM regions south of the WTP (Figs. 11b, c), the Kunlun Mountains north of the WTP, northern Europe, and northeastern Asia. The locations of the prescribed forcing are shown in Fig. 11a. The LBM model reproduces the tropical Kelvin wave response when diabatic heating is located over the tropical Indian Ocean and shows a superposition of the tropical Kelvin wave and the Gill-type Rossby wave response to Indian Peninsula heating, but the eastward-propagating wave train over the mid-latitude of Asia along the westerly jet stream is unclear. Previous studies have founded that the diabatic heating in western-central India is more efficient than that in the Indian Peninsula in modulating the CGT main centers over mid-latitude Asia (Wu 2002; Wu and Wang 2002). Such feature is consistent with the result of LBM experiments in our study. However, there is no apparent wave-like response in the LBM model when the diabatic heating moves to the north of the WTP, and the heating over northern Europe and northeastern Asia does not feedback on the CGT-like teleconnection pattern. The atmospheric response to the heating over southern Europe is not shown because the result is consistent with that of Lin et al. (2017a; their Fig. 9a) and the response is mainly concentrated over Eurasia.

In general, the two-wavetrain structure of the TP-CGT can only be formed by the prescribed heating anomaly over the WTP. The heating over the ISM region (southern Europe) can only induce westward (eastward) propagating Rossby wave response, which is located over northern Africa (Eurasia) and only affects part of the CGT. The WTP heat 


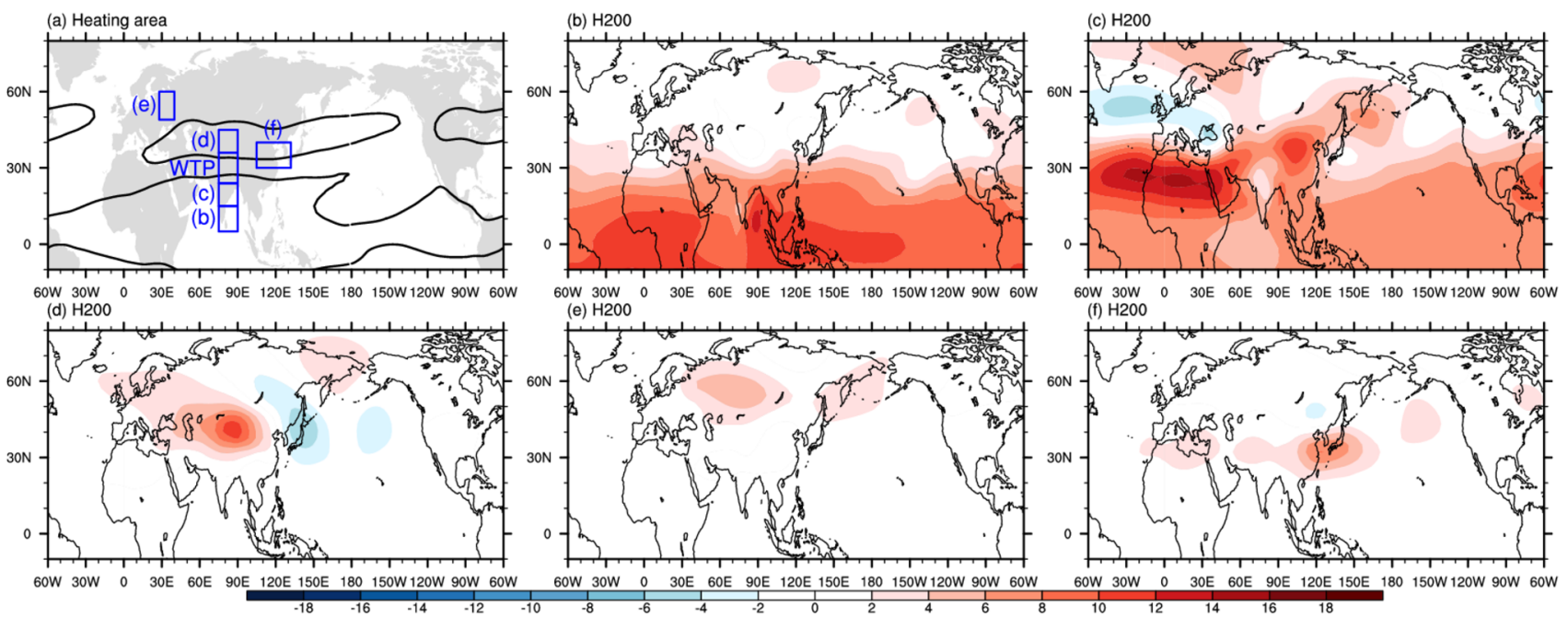

Fig. 11 a Distribution of the prescribed heat forcing in each simulation experiment of the LBM model. Blue boxes indicate the locations of heating anomalies. The letter near each box corresponds to the serial number of the steady response to this area's heat forcing. b-f
The averaged steady responses of $\mathrm{H} 200$ from day 26 to day 30 to the prescribed heat forcing over the areas in (a). The background mean state used in the LBM model experiments is taken from the summer mean (JJAS) climatology for the time period 1980-2018 source therefore plays an important role in the CGT pattern, and the meridional location of the WTP is responsible for this phenomenon. Therefore, we suggest that the WTP plays a "pit stop" transit role in transferring the variability of the ISM to the CGT pattern. The circulation anomaly is responsible for other anomalous heating that is sensitive to the CGT pattern. Cloud cover or vertical motion would be affected in these regions.

\section{Discussion and conclusions}

This study investigates the summer circumglobal teleconnection pattern induced by the synchronous WTP heating and reveals the connections between different diabatic heating components and the CGT pattern using both reanalysis data and numerical models.

The first dominant coupled mode between the TP area heating and the northern hemispheric H200 shows a significant connection between the WTP heating and the CGT-like teleconnection pattern. The second coupled mode displays a dipole pattern of the TP heating and the tropical atmospheric circulation anomaly. The first two modes explain $>60 \%$ of the total covariance between the two fields and the WTP heat source is significantly associated with the H200 in both modes, suggesting the important role of the WTP heating in the upper troposphere of the northern hemisphere.

The composite differences between the strongly positive and negative WTP-averaged heating years indicate that the vertically-integrated heat source anomaly is strongest over the southwestern WTP, suggesting the importance of ascending motion in the LH release forced by the largescale orography. The strongest atmospheric heating rate is $>1.8 \mathrm{~K} \mathrm{day}^{-1}$ at the boundary of the southwestern slopes. The anomalous heating over the main body of the WTP is stronger than that over the surroundings at the same pressure level. This strong anomalous heating can extend to the tropopause with a similar magnitude as the climatological heating of $>1 \mathrm{~K} \mathrm{day}^{-1}$.

The H200 field associated with the anomalous heating of the WTP shows a clear CGT-like pattern, with six anomalous high centers in the North Atlantic, North Africa, the western TP, northeastern Asia, the west coast of North America, and the Gulf of Mexico. The latent heat release from the WTP contributes to this connection, called the TPCGT, but the surface sensible heating corresponds to a wave train propagating from North Japan to central North America through the Bering Sea and Canada. A reversed T-shaped circulation anomaly and a wavenumber- 4 wave train over Eurasia are associated with the radiative heating over the WTP. The high-elevation heat source of the WTP is accompanied by a significant anomalous high over remote areas, but the low-elevation heat source corresponds to strong local circulation. The blocking effect of the topography accounts for the difference.

The TP-CGT has a two-direction structure induced by the anomalous WTP HS: a westward-propagating Gill-type Rossby wave along the south of WTP and an eastward-propagating wave train along the westerly jet stream. The running lead-lag correlation shows that the WTP heat source leads the TP-CGT centers in North Africa and northeastern Asia by 1-8 days, which confirms the counter-propagation of the 
WTP diabatic heat energy. The steady response to the WTP heating in the LBM model is consistent with this observational feature. The enhanced TP-CGT is also verified by the AGCM model with amplified WTP diabatic heating according to the WTP-averaged heating profile. The percentage of variance of the CGT pattern rises about $3 \%$ when injecting the WTP heating in the ACGM model. The interaction between the TP-CGT and the basic flow is intensified in both the observations and the AGCM model.

The CGT has been regarded as an internal dynamic mode, and the diabatic heating in specific regions can excite a CGT-like response. To detect the contribution of diabatic heating to the CGT in the observations, a regression-out method is applied to Eurasia by removing the contribution of heating at each gird point to the CGT pattern and then calculating the change in the percentage variance of the CGT. The results show that the latent heat release from the WTP explains $>18 \%$ of the CGT variance in the northern hemisphere. The atmospheric radiative heating over the Mediterranean and North Africa is strongly associated with the CGT pattern, indicating the importance of the monsoon-desert mechanism caused by the westward-propagating Gill-type Rossby wave. Sensible heating in northern Europe has a similar magnitude, but makes an opposite contribution to the CGT pattern relative to latent heating. The correlation coefficient between the two heating components is -0.92 .

A tropical Kelvin wave is excited by heating in the tropical ISM region, and extratropical heating can cause a superposition of the tropical Kelvin wave and Gill-type Rossby wave response. The northern Europe and northeastern Asia also relate to the CGT pattern, but no circumglobal response can be induced by heating of the two regions. A CGT with a clear two-direction structure can only be formed if the prescribed heating is located in the WTP. The evidence derived from observations and the LBM model simulations suggests the unique role of WTP heating in the mid-latitude circulation of the northern hemisphere. The transports of moisture by the ISM and the topographic uplift effect account for the strong WTP heat source during the summer and the WTP acts as a "pit stop" to relay the impact of the ISM on the CGT.

Our study confirms the effect of heating by the TP on the upstream climate and illustrates the TP-CGT circumglobal response excited by the diabatic heating of the WTP. Only the one-way effect of the WTP on the CGT-like pattern has been detected. The CGT pattern can interact with ISM and further affect the TP rainfall. Following Jiang and Ting (2017), the positive phase of the CGT will promote the central- northern Indian subcontinent rainfall, which varies in phase with the WTP rainfall. The strong WTP rainfall can further strength the CGT-like pattern to form a positive feedback process. However, the interactions between the mid-latitude teleconnection pattern and the WTP heating have not been proved. While this study is focused on the interannual variability of the WTP heating, strong interseasonal oscillations occur in both CGT pattern and TP heating (Ding and Wang 2007; Ren et al. 2019; Wang and Duan 2015) and the connection between the different time scales is still unclear. Furthermore, the heating of the WTP shows a significant relationship with the polar circulation, and the wave train associated with the radiative heating of low elevation is originated from the Ural, which is similar to the wave train shown by Li et al. (2020a). Therefore, we speculate that the polar circulation is associated with the Arctic sea ice variability. Apparently, these issues require further investigations.

Supplementary Information The online version contains supplementary material available at https://doi.org/10.1007/s00382-021-05841-6.

Acknowledgements This study was jointly supported by the Strategic Priority Research Program of the Chinese Academy of Sciences (Grant XDA20100304), the Second Tibetan Plateau Scientific Expedition and Research Program of China (Grant 2019QZKK0208), the National Natural Science Foundation of China (Grants 41790471, 91637208, and 41975054), the National Key Research and Development Program of China (Grants 2016YFA0602200 and 2019YFC1510400), and Guangdong Province Key Laboratory for Climate Change and Natural Disaster Studies (Grant 2020B1212060025).

Open Access This article is licensed under a Creative Commons Attribution 4.0 International License, which permits use, sharing, adaptation, distribution and reproduction in any medium or format, as long as you give appropriate credit to the original author(s) and the source, provide a link to the Creative Commons licence, and indicate if changes were made. The images or other third party material in this article are included in the article's Creative Commons licence, unless indicated otherwise in a credit line to the material. If material is not included in the article's Creative Commons licence and your intended use is not permitted by statutory regulation or exceeds the permitted use, you will need to obtain permission directly from the copyright holder. To view a copy of this licence, visit http://creativecommons.org/licenses/by/4.0/.

\section{References}

Ambrizzi T, Hoskins BJ, Hsu HH (1995) Rossby wave propagation and teleconnection patterns in the austral winter. J Atmos Sci 52:3661-3672

An W, Hou S, Zhang W, Wang Y, Liu Y, Wu S, Pang H (2016) Significant recent warming over the northern Tibetan Plateau from ice core $\delta 180$ records. Climate of the past 12:201-211

An W, Hou S, Hu Y, Wu S (2017) Delayed warming hiatus over the Tibetan Plateau. Earth and Space Science 4:128-137

Bretherton CS, Smith CA, Wallace JM (1992) An intercomparison of methods for finding coupled patterns in climate data. J Climate 5:541-560

Chen G, Huang R, Zhou L (2013) Baroclinic instability of the silk road pattern induced by thermal damping. J Atmos Sci 70:2875-2893

Ding Q, Wang B (2005) Circumglobal teleconnection in the northern hemisphere summer. J Climate 18:3483-3505

Ding Q, Wang B (2007) Intraseasonal teleconnection between the summer Eurasian wave train and the Indian monsoon. J Climate 20:3751-3767 
Ding Q, Wang B, Wallace JM, Branstator G (2011) Tropical-extratropical teleconnections in boreal summer: observed interannual variability. J Climate 24:1878-1896

Dong L, Xu X, Zhao T, Ren H (2019) Linkage between moisture transport over the Yangtze River Basin and a critical area of the Tibetan Plateau during the Meiyu. Clim Dyn 53:2643-2662

Duan A, Wu G (2005) Role of the Tibetan Plateau thermal forcing in the summer climate patterns over subtropical Asia. Clim Dyn 24:793-807

Duan A, Wu G (2008) Weakening trend in the atmospheric heat source over the Tibetan plateau during recent decades Part I: Observations. J Clim 21:3149-3164

Duan A, Xiao Z (2015) Does the climate warming hiatus exist over the Tibetan Plateau? Sci Rep 5:13711

Duan A, Li F, Wang M, Wu G (2011) Persistent weakening trend in the spring sensible heat source over the Tibetan Plateau and its impact on the Asian summer monsoon. J Climate 24:5671-5682

Duan A, Wang M, Lei Y, Cui Y (2013) Trends in summer rainfall over China associated with the Tibetan Plateau sensible heat source during 1980-2008. J Climate 26:261-275

Enomoto T, Hoskins BJ, Matsuda Y (2003) The formation mechanism of the Bonin high in August. Q J R Meteorol Soc 129:157-178

Gadgil S (2003) The Indian monsoon and its variability. Annu Rev Earth Planet Sci 31:429-467

Gelaro R et al (2017) The modern-era retrospective analysis for research and applications, version 2 (MERRA-2). J Climate 30:5419-5454

Gill AE (1980) Some simple solutions for heat-induced tropical circulation. Q J R Meteorol Soc 106:447-462

Harris I, Osborn TJ, Jones P, Lister D (2020) Version 4 of the CRU TS monthly high-resolution gridded multivariate climate dataset. Scientific Data 7:109

He S, Yang S, Li Z (2017) Influence of latent heating over the Asian and western Pacific monsoon region on Sahel ssummer rainfall. Sci Rep 7:7680-7680

Hersbach $\mathrm{H}$ et al (2020) The ERA5 global reanalysis. Q J R Meteorol Soc 146:1999-2049

Hoskins BJ, Ambrizzi T (1993) Rossby wave propagation on a realistic longitudinally varying flow. J Atmos Sci 50:1661-1671

Hu Z-Z, Nitta T (1997) Seasonality of interaction between convection over the western Pacific and general circulation in the northern hemisphere. Adv Atmos Sci 14(4):541-553

Hu Z-Z, Wu R, Kinter LJ, Yang S (2005) Connection of summer rainfall variations in South and East Asia: Role of El Niño-Southern Oscillation. Int J Climatol 25:1279-1289

Huang G, Liu Y, Huang R (2011) The interannual variability of summer rainfall in the arid and semiarid regions of Northern China and its association with the northern hemisphere circumglobal teleconnection. Adv Atmo Sci 28:257-268

Ji P, Yuan X, Li D (2020) Atmospheric radiative processes accelerate ground surface warming over the southeastern Tibetan Plateau during 1998-2013. J Climate 33:1881-1895

Jiang X, Ting M (2017) A dipole pattern of summertime rainfall across the Indian subcontinent and the Tibetan Plateau. J Climate 30:9607-9620

Jiang X, Ting M (2019) Intraseasonal variability of rainfall and its effect on interannual variability across the Indian subcontinent and the Tibetan Plateau. J Climate 32:2227-2245

Jiang X, Li Y, Yang S, Yang K, Chen J (2016) Interannual variation of summer atmospheric heat source over the Tibetan Plateau and the role of convection around the western Maritime Continent. J Clim 29:121-138

Kanamitsu M, Ebisuzaki W, Woollen J, Yang S, Hnilo JJ, Fiorino M, Potter GL (2002) NCEP-DOE AMIP-II reanalysis (R-2). Bull Amer Meteorol Soc 83:1631-1643
Kosaka Y, Nakamura H (2006) Structure and dynamics of the summertime Pacific-Japan teleconnection pattern. Q J R Meteorol Soc 132(619):2009-2030

Kosaka Y, Nakamura H, Watanabe M, Kimoto M (2009) Analysis on the dynamics of a wave-like teleconnection pattern along the summertime Asian jet based on a reanalysis dataset and climate model simulations. J Meteorol Soc Japan Ser II 87(3):561-580

Krishnan R, Sugi M (2001) Baiu rainfall variability and associated monsoon teleconnections. J Meteorol Soc Japan Ser II 79:851-860

Li Q, Yang S, Kousky VE, Higgins RW, Lau K-M, Xie P (2005) Features of cross-Pacific climateshown in the variability of China and US precipitation. Int J Climatol 25:1675-1696

Li Z, Yang S, He B, Hu C (2016) Intensified springtime deep convection over the South China Sea and the Philippine sea dries southern China. Sci Rep 6:30470-30470

Li F, Wan X, Wang H, Orsolini YJ, Cong Z, Gao Y, Kang S (2020a) Arctic sea-ice loss intensifies aerosol transport to the Tibetan Plateau. Nat Clim Chang 10:1037-1044

Li Q, Wang J, Yang S, Wang F, Wu J, Hu Y (2020b) Sub-seasonal prediction of rainfall over the South China Sea and its surrounding areas during spring-summer transitional season. Int J Climatol 40(10):4326-4346

Li Q, Wang T, Wang F, Liang X-Z, Zhao C, Dong L, Zhao C, Xie B (2021) Dynamical downscaling simulation of the East Asian summer monsoon in a regional Climate-Weather Research and Forecasting model. Int J Climatol 41:E1700-E1716

Lin Z, Lu R (2016) Impact of summer rainfall over southern-central Europe on circumglobal teleconnection. Atmos Sci Lett $17: 258-262$

Lin H, Wu Z (2011) Contribution of the autumn Tibetan Plateau snow cover to seasonal prediction of North American winter temperature. J Climate 24:2801-2813

Lin C, Yang K, Qin J, Fu R (2013) Observed coherent trends of surface and upper-air wind speed over China since 1960. J Climate 26:2891-2903

Lin Z, Liu F, Wang B, Lu R, Qu X (2017a) Southern European rainfall reshapes the early-summer circumglobal teleconnection after the late 1970s. Clim Dyn 48:3855-3868

Lin Z, Lu R, Wu R (2017b) Weakened impact of the Indian early summer monsoon on North China rainfall around the late 1970s: Role of basic-state change. J Climate 30:7991-8005

Liu S, Wu Q, Ren X et al (2017) Modeled northern hemisphere autumn and winter climate responses to realistic Tibetan Plateau and Mongolia snow anomalies. J Climate 30:9435-9454

Liu S, Wu Q, Schroeder S et al (2020a) Near-global atmospheric responses to observed springtime Tibetan Plateau snow anomalies. J Clim 33:1691-1706

Liu Y, Lu M, Yang H, Duan A, He B, Yang S, Wu G (2020b) Landatmosphere-ocean coupling associated with the Tibetan Plateau and its climate impacts. Nat Sci Rev 7:534-552

Lu R, Oh JH, Kim BJ (2002) A teleconnection pattern in upper-level meridional wind over the North African and Eurasian continent in summer. Tellus a: Dyn Meteorol Oceano 54:44-55

Lu M, Yang S, Li Z, He B, He S, Wang Z (2018) Possible effect of the Tibetan Plateau on the "upstream" climate over West Asia, North Africa, South Europe and the North Atlantic. Clim Dyn 51:1485-1498

Lu M, Huang B, Li Z, Yang S, Wang Z (2019) Role of Atlantic air-sea interaction in modulating the effect of Tibetan Plateau heating on the upstream climate over Afro-Eurasia-Atlantic regions. Clim Dyn 53:509-519

Lu M, Yang S, Wang J, Wu Y, Jia X (2021) Response of regional Asian summer monsoons to the effect of reduced surface albedo in different Tibetan Plateau domains in idealized model experiments. J Climate accepted 
Mote TL, Kutney ER (2012) Regions of autumn Eurasian snow cover and associations with North American winter temperatures. Int J Climatol 32:1164-1177

Neale RB et al (2010) Description of the NCAR community atmosphere model (CAM 5.0). NCAR Tech. Note NCAR/TN-486+ STR $1: 1-12$

Nitta T (1987) Convective activities in the tropical western Pacific and their impact on the northern hemisphere summer circulation. J Meteorol Soc Japan Ser II 65:373-390

Qian Q, Jia X, Wu R (2019) Changes in the impact of the autumn Tibetan Plateau snow cover on the winter temperature over North America in the mid-1990s. J Geophy Res: Atmos 124:10321-10343

Qin J, Yang K, Liang S, Guo X (2009) The altitudinal dependence of recent rapid warming over the Tibetan Plateau. Clim Change 97:321

Qiu J (2008) China: the third pole. Nature 454:393-396

Ren R, Zhu C, Cai M (2019) Linking quasi-biweekly variability of the South Asian high to atmospheric heating over Tibetan Plateau in summer. Clim Dyn 53:3419-3429

Rodwell MJ, Hoskins BJ (1996) Monsoons and the dynamics of deserts. Q J R Meteorol Soc 122:1385-1404

Saeed S, Müller WA, Hagemann S, Jacob D, Mujumdar M, Krishnan R (2011) Precipitation variability over the South Asian monsoon heat low and associated teleconnections. Geophy Res Lett 38:L08702

Sato N, Takahashi M (2006) Dynamical processes related to the appearance of quasi-stationary waves on the subtropical jet in the midsummer northern hemisphere. J Climate 19:1531-1544

Schiemann R, Luthi D, Schar C (2009) Seasonality and interannual variability of the westerly jet in the Tibetan Plateau region. J Climate 22:2940-2957

Song L, Wu R, An L (2019) Different sources of 10- to 30-day intraseasonal variations of autumn snow over western and eastern Tibetan Plateau. Geophy Res Lett 46:9118-9125

Sun J, Wang H (2012) Changes of the connection between the summer North Atlantic Oscillation and the East Asian summer rainfall. J Geophy Res 117:D08110

Takaya K, Nakamura H (2001) A formulation of a phase-independent wave-activity flux for stationary and migratory quasigeostrophic eddies on a zonally varying basic flow. J Atmos Sci 58:608-627

Wallace JM, Smith CA, Bretherton CS (1992) Singular value decomposition of wintertime sea surface temperature and $500-\mathrm{mb}$ height anomalies. J Clim 5:561-576

Wang M, Duan A (2015) Quasi-biweekly oscillation over the Tibetan Plateau and its link with the Asian summer monsoon. J Clim 28:4921-4940

Wang M, Zhou S, Duan A (2012) Trend in the atmospheric heat source over the central and eastern Tibetan Plateau during recent decades: comparison of observations and reanalysis data. Chin Sci Bull 57:548-557

Wang L, Xu P, Chen W, Liu Y (2017) Interdecadal variations of the Silk Road pattern. J Climate 30:9915-9932

Wang Z, Yang S, Duan A, Hua W, Ullah K, Liu S (2019) Tibetan Plateau heating as a driver of monsoon rainfall variability in Pakistan. Clim Dyn 52:6121-6130

Wang Z, Wu R, Duan A, Qu X (2020) Influence of eastern Tibetan Plateau spring snow cover on North American air temperature and its interdecadal change. J Climate 33:5123-5139

Watanabe M, Kimoto M (2000) Atmosphere-ocean thermal coupling in the North Atlantic: a positive feedback. Q J R Meteorol Soc 126:3343-3369

Wu R (2002) A mid-latitude Asian circulation anomaly pattern in boreal summer and its connection with the Indian and East Asian summer monsoons. Int J Climatol 22:1879-1895
Wu L et al (2018) Preliminary assessment on the hindcast skill of the arctic oscillation with decadal experiment by the BCC_CSM1.1 climate model. Adv Clim Change Res 9(4):209-217

Wu R, Wang B (2002) A contrast of the East Asian summer monsoon-ENSO relationship between 1962-77 and 1978-93. J Climate 15:3266-3279

Wu G, Zhang Y (1998) Tibetan Plateau forcing and the timing of the monsoon onset over South Asia and the South China Sea. Mon Wea Rev 126:913-927

Wu R, Hu Z-Z, Kirtman BP (2003) Evolution of ENSO-related rainfall anomalies in East Asia. J Clim 16:3742-3758

Wu Q, Hu H, Zhang L (2011) Observed influences of autumn-early winter Eurasian snow cover anomalies on the hemispheric PNAlike variability in winter. J Clim 24:2017-2023

Wu R, Zhao P, Liu G (2014a) Change in the contribution of spring snow cover and remote oceans to summer air temperature anomaly over Northeast China around 1990. J Geophy Res Atmos 119(2):663-676

Wu R, Liu G, Zhao P (2014b) Contrasting Eurasian spring and summer climate anomalies associated with western and eastern Eurasian spring snow cover changes. J Geophy Res Atmos 119(2):7410-7424

Wu B, Lin J, Zhou T (2016a) Interdecadal circumglobal teleconnection pattern during boreal summer. Atmos Sci Lett 17:446-452

Wu B, Zhou T, Li T (2016b) Impacts of the Pacific-Japan and circumglobal teleconnection patterns on the interdecadal variability of the East Asian summer monsoon. J Clim 29:3253-3271

Wu Z, Zhang P, Chen H, Li Y (2016c) Can the Tibetan Plateau snow cover influence the interannual variations of Eurasian heat wave frequency? Clim Dyn 46:3405-3417

Xu X, Lu C, Shi X, Gao S (2008) World water tower: an atmospheric perspective. Geophy Res Lett 35:L20815

Xu X et al (2014) An important mechanism sustaining the atmospheric "water tower" over the Tibetan Plateau. Atmos Chem Phys 14:11287-11295

Yanai M (1961) A detailed analysis of typhoon formation. J Meteor Soc Japan Ser II 39:187-214

Yanai M, Esbensen S, Chu JH (1973) Determination of bulk properties of tropical cloud clusters from large-scale heat and moisture budgets. J Atmos Sci 30(4):611-627

Yang S, Webster PJ, Dong M (1992) Longitudinal heating gradient: another possible factor influencing the intensity of the Asian summer monsoon circulation. Adv Atmos Sci 9:397-410

Yang K, Guo X, He J, Qin J, Koike T (2011) On the climatology and trend of the atmospheric heat source over the Tibetan Plateau: an experiments-supported revisit. J Climate 24:1525-1541

Yao T et al (2012) Different glacier status with atmospheric circulations in Tibetan Plateau and surroundings. Nat Clim Chang 2:663-667

Yao T et al (2017) From Tibetan plateau to third pole and pan-third pole. Bull Chin Acad Sci 32:924-931

Yao T et al (2019) Recent third pole's rapid warming accompanies cryospheric melt and water cycle intensification and interactions between monsoon and environment: multidisciplinary approach with observations, modeling, and analysis. Bull Amer Meteorol Soc 100:423-444

Yasui S, Watanabe M (2010) Forcing processes of the summertime circumglobal teleconnection pattern in a dry AGCM. J Climate 23:2093-2114

Yuan J, Li W, Deng Y (2015) Amplified subtropical stationary waves in boreal summer and their implications for regional water extremes. Environ Res Lett 10:104009

Zhang C, Tang Q, Chen D (2017) Recent changes in the moisture source of precipitation over the Tibetan Plateau. J Climate 30:1807-1819 
Zhao P, Chen L (2000) Calculation of solar albedo and radiation equilibrium over the Qinghai-Xizang Plateau and analysis of their climatic features. Adv Atoms Sci 17:140-156

Zhao P, Zhou Z, Liu J (2007) Variability of Tibetan spring snow and its associations with the hemispheric extratropical circulation and East Asian summer monsoon rainfall: an observational investigation. J Clim 20(15):3942-3955
Publisher's Note Springer Nature remains neutral with regard to jurisdictional claims in published maps and institutional affiliations. 